PAPERS IN PHYSICAL OCEANOGRAPHY AND METEOROLOGY

PUBLISHED BY

\author{
MASSACHUSETTS INSTITUTE OF TECHNOLOGY \\ AND \\ WOODS HOLE OCEANOGRAPHIC INSTITUTION
}

Vol. XI, No. 3

\title{
AN ELECTROMAGNETIC METHOD FOR MEASURING THE VELOCITIES OF OCEAN CURRENTS FROM A SHIP UNDER WAY
}

BY

WILLIAM S. von ARX

WOODS HOLE OCEANOGRAPHIC INSTITUTION

REFERENCE IIBRARY

DOCUMENT COLLECTION

CAMBRIDGE AND WOODS HOLE, MASSACHUSETTS

$$
\text { March, I950. }
$$




\section{PAPERS IN PHYSICAL OCEANOGRAPHY AND METEOROLOGY}

\section{Meteorological Papers}

(In continuation of Meteorological Papers)

Vol. I, No. I. H. C. Willett: Synoptic Studies in Fog, I930.

Out of Print

No. 2. Horace R. Byers: Characteristic Weather Phenomena of California, I93I.

No. 3. C.-G. Rossby: Thermodynamics Applied to Air Mass Analysis, I932.

No. 4. C.-G. Rossby: A Generalization of the Theory of the Mixing Length with Applications to Atmospheric and Oceanic Turbulence, I932. Out of Print

\section{Papers in Physical Oceanography and Meteorology}

Vol. II, No. I. H. U. Sverdrup and F. M. Soule: Scientific Results of the "Nautilus" Expedition, I93I, Parts I to III, I933.

No. 2. H. C. Willett: American Air Mass Properties, I933.

No. 3. B. Villinger and Henry C. Stetson: Scientific Results of the "Nautilus" Expedition, I93I, Parts IV and V, I933.

No. 4. Henry B. Bigelow: Studies of theWaters on the Continental Shelf, Cape Cod to Chesapeake Bay, I. The Cycle of Temperature, I933.

Vol. III, No. I. H. R. Seiwell: The Distribution of Oxygen in the Western Basin of the North Atlantic, I934.

No. 2. K. O. Lange and C. S. Draper: The Meteorological Airplane Ascents of the Massachusetts Institute of Technology, I934.

No. 3. C.-G. Rossby and R. B. Montgomery: The Layer of Frictional Influence in Wind and Ocean Currents, I935.

No. 4. H. R. Seiwell: The Cycle of Phosphorus in the Western Basin of the North Atlantic, I. Phosphate Phosphorus, 1935.

Vol. IV, No. I. Henry B. Bigelow and Mary Sears: Studies of the Waters on the Continental Shelf, Cape Cod to Chespeake Bay, II. Salinity, I935.

No. 2. H.C. Willett: Discussion and Illustration of Problems Suggested by the Analysis of Atmospheric Cross-Sections, 1935.

No. 3. C.-G. Rossby and R. B. Montgomery: On the Momentum Transfer at the Sea Surface, I936.

No. 4. C.O'D. Iselin: A Study of the Circulation of the Western North Atlantic, 1936.

Vol. V, No. I. C.-G. Rossby: Dynamics of Steady Ocean Currents in the Light of Experimental Fluid Mechanics, 1936.

No. 2. H. R. Seiwell: Short Period Vertical Oscillations in the Western Basin of the North Atlantic, I937.

No. 3. H. R. Seiwell: The Minimum Oxygen Concentration in the Western Basin of the North Atlantic, I937.

No. 4. Henry C. Stetson: The Sediments of the Continental Shelf off the Eastern Coast of the United States, $193^{8}$.

\footnotetext{
* Requests for this number should be addressed to Meteorological Department, Massachusetts Institute of Technology, Cambridge, Massachusetts.

† Requests for this number should be addressed to Woods Hole Oceanographic Institution, Woods Hole, Massachusetts.
} 
PAPERS IN PHYSICAL OCEANOGRAPHY AND METEOROLOGY

PUBLISHED BY

MASSACHUSETTS INSTITUTE OF TECHNOLOGY

AND

WOODS HOLE OCEANOGRAPHIC INSTITUTION

$$
\text { Vol. XI, No. } 3
$$

\section{AN ELECTROMAGNETIC METHOD FOR MEASURING THE VELOCITIES OF OCEAN GURRENTS FROM A SHIP UNDER WAY \\ BY \\ WILLIAM S. von ARX}

Contribution No. 499 from the Woods Hole Oceanograpbic Institution

CAMBRIDGE AND WOODS HOLE, MASSACHUSETTS

March, $195^{\circ}$ 


\section{CONTENTS}

INTRODUCTION

I. The General Problem of Kinematic Observation of the Deep Sea . 7

II. Introduction to the Deep Sea Electromagnetic Method . . . . . 9

I. The Development of the Geomagnetic Electrokinetograph . . . . Io

III. Physical Principles of the Electromagnetic Method _. . . . . . 12

IV. On the Validity of the Electromagnetic Method . . . . . . . . i6

I. The " $k$ " factor . . . . . . . . . . . . . . . . . 16

2. Discussion of Tests of the Validity of the Method . . . . . . 18

3. Some Oceanographic Data Derived from the Tests of the Method . . 32

V. Practical Considerations . . . . . . . . . . . . . . . . . . . . . 36

I. Instrumental Sensitivity . . . . . . . . . . . . . . 36

2. The Wave Signal . . . . . . . . . . . . . . . . . . $\quad .38$

VI. Instrumentation and Shipboard Practice . . . . . . . . . . . . $4^{\mathrm{I}}$

I. Potentiometer Recorders and Power Supply . . . . . . . . $4^{\mathrm{I}}$

2. Cables . . . . . . . . . . . . . . . . . . . 43

3. Electrode Pairs . . . . . . . . . . . . . . . . . . 45

4. Electrochemical Errors of Electrodes . . . . . . . . . . 48

5. The Sailings. . . . . . . . . . . . . . . . . . 49

6. The Reduction of Observations at Sea . . . . . . . . . . . 53

VII. Application of the Electromagnetic Method to Observations in Shoal

WATER . . . . . . . . . . . . . . . . . 57

I. Observations while Under Way . . . . . . . . . . . . . . 57

2. Observations at a Fixed Station . . . . . . . . . . . 59

References . . . . . . . . . . . . . . . . . . . . 6I 


\section{INTRODUCTION}

During the past four years a deliberate effort has been made at the Woods Hole Oceanographic Institution to devise methods of kinematic observation generally suited to the needs of oceanographers. One result of this work, the electromagnetic method, has been brought from the experimental stage to one of useful maturity. Many of the theoretical potentialities of the method are still to be explored and developed. Nevertheless it seems likely that this remaining work may be done more soundly if present developments of the theory and instrumentation are made available for use and evaluation by: others.

These studies in methods of kinematic observation have been supported mainly under the provisions of Bureau of Ships Contract NObs-2083, and Office of Naval Research Contract N6onr-277-I. This support and the assistance of the Naval Ordnance Laboratory, the Hydrographic Office (Oceanographic Division), the United States Coast Guard, and the David Taylor Model Basin of the United States Navy is gratefully acknowledged. 


\section{THE GENERAL PROBLEM OF KINEMATIC OBSERVATION OF THE DEEP SEA}

The task of describing the broad features of the circulation of the oceans has been accomplished largely by indirect methods and without the benefit of simultaneous observations. Except for a scattered few direct observations of water motion and the data from ships' logs, the bulk of the present kinematic description of the deep sea is inferred from dynamic observations. The method of dynamic sections, while fundamental to many phases of oceanographic work, is based on certain dynamic principles and is therefore incapable of yielding kinematic data free from the uncertainty of these principles. Direct observations made with conventional current meters suspended from anchored ships are so time-consuming that it is difficult to obtain synoptic information. These observations are also somewhat uncertain, for at an average distance of 4 kilometers from the anchor, the motion of the ship is ponderous and incessant. Measurements made from drifting ships are probably more reliable, but equally time-consuming and no less difficult to correlate in space and time. In view of the enormous volume of water that must be surveyed again and again, and the inaccessibility of the bottom as a frame of reference, it is easy to see why indirect methods have been used so widely and how urgent is the need for more rapid surveying techniques that yield sufficient kinematic data for essentially synoptic studies to be made of a modest portion of an ocean at a time.

During the past decade improved methods have been devised for observing ocean currents from moving ships. Thus far these methods are limited to the surface and near-surface layers. Nevertheless, the mobility of the ship permits something to be discerned of the synoptic pattern of flow and its changes. The simplest and most familiar of these methods takes its data from consecutive Loran fixes at 20 or 30 minute intervals while the ship is under way. The difference between the true geographic progress of the ship and the dead reckoning of the speed and course steered shows the combined effects of wind and current. The kinematic detail obtained by this method is improved if the ship is propelled slowly but it is found on slowing the ship, that it is more seriously drifted by the wind.

Greater kinematic detail free of the influence of the wind and the ship's speed has been obtained electromagnetically with respect to the reference frame provided by the earth's magnetic field. Theoretically, the electromagnetic principle allows continuous measurement of the mean and turbulent motions of the sea at any chosen level and at any rate at which the measuring apparatus can be propelled. The method is presently implemented by the Geomagnetic Electrokinetograph, a shipboard instrument capable of indicating and recording surface and near-surface velocity components normal to the direction of motion of the ship. These data collected on two courses at an angle to each other can be composed to fix the true horizontal velocity vector. The shortest practical run along each course is about 500 meters. This limitation is imposed partly by the apparatus and partly by the necessity of averaging out the turbulent irregularities of motion in the sea itself. The motion in what are thought to be turbulent systems as small as too meters across can be detected, but their internal details can be studied only if the systems are large enough to permit the ship to maneuver within their bound- 
aries. Larger features of the sea can be studied by lengthening the run between course changes and arranging the pattern of true current determinations to reveal more clearly the changes observed in the record of one component of flow. Systematic changes of course are more often used to gather a uniformly distributed series of true current fixes.

The electromagnetic principle of measurement is purely kinematic in the sense that no assumptions are made regarding the causes of the water motion or the forces at work within it. The present techniques of measurement appear to be sound and practical at sea. The accuracy of the method is highest on the surface over deep water where the combined errors of measurement probably do not exceed ten per cent. 


\section{INTRODUCTION TO THE DEEP SEA ELECTROMAGNETIC METHOD}

The deep sea electromagnetic method is based on a suggestion made by Faraday in the Bakerian Lecture of 1832 before the Royal Society: "Theoretically, it seems a necessary consequence that where water is flowing, there electric currents should be formed: thus, if a line be imagined passing from Dover to Calais through the sea, and returning through the land beneath the water to Dover, it traces out a circuit of conducting matter, one part of which, when the water moves up or down the channel, is cutting the magnetic curves of the earth, whilst the other is relatively at rest." Faraday (I832) attempted to detect electric currents flowing over a short range in response to the water motions of the Thames, but the potentials developed at the copper electrodes he used masked the effect. Following the middle of the Igth century, however, the effect was noted repeatedly on the very long ranges provided by broken submarine telegraph cables. These observations are summarized by Longuet-Higgins (1949). Successful short range experiments were conducted in Dartmouth Harbor in 1918 by Young, Gerrard and Jevons (1920) who used both moored and drifting non-polarizing electrodes to reveal the existence of electric currents generated by tidal motions. More recently Barber and Longuet-Higgins (1948), Barber (I948) and Longuet-Higgins (I947, I949) have detected and described theoretically the potential differences and associated magnetic effects produced by the flow of water in the English Channel.

Along with these natural observations, many applications of motional electromagnetic effects in liquids have been made in instruments for metering or detecting flow for biological and physical studies. Some of these are reviewed by Fabre (1932), Kolin (I936, I944, I945), Wetterer (I937, I938), Einhorn (1939), Thürlemann (I94I), and Guelcke and Schoute-Vanneck (I946). The latter developed an electromagnetic flow meter for use on the sea floor. The theory of this instrument has been investigated by Longuet-Higgins and Barber (1946). Instrumental applications of the principle of electromagnetic induction in liquids usually employ direct or alternating artificial magnetic fields. Since these are commonly generated by a component part of the instrument, observations of motion are made with regard to the instrument as a frame of reference. The Geomagnetic Electrokinetograph, as its name implies, makes use of the undisturbed magnetic flux of the earth as the frame of reference for observations at sea. ${ }^{1}$

The essential physical equipment that constitutes the surface Electrokinetograph is: (I) a pair of electrodes mounted a few tens of meters apart on a two-conductor cable long enough to stream them astern away from the influences of the ship and connect them to, (2) a recording potentiometer on board. With this equipment and the ship's compass, observations are made under way of the direction and the potential difference between the electrodes. These potential differences are due to the water motion at right angles to the course and are rigidly related to the drift and set of the ship and electrodes. The potential difference changes sign when currents set the ship to port or to starboard. The magnitude of the potential difference depends on the rate of drift

\footnotetext{
1 The steadiness of the earth's magnetic flux as a reference frame has been studied and found to be sufficient for oceancgraphic observations by this method even during magnetic storms. Magnetic storms rarely involve fluctuations of magnetic intensity greater than one per cent of the total field intensity. Such fluctuations, though ineffective by themselves, may be rapid enough to produce strong earth currents by induction. It is found that potential differences accompanying earth currents are much smaller in the sea than on land. Thus far, no clear indications of interference from fluctuations of magnetic intensity or earth currents have been detected in Electrokinetograph records. The possibility of occasional interference exists, however, particularly in shoal waters near the land.
} 
normal to the course, the length of wire between electrodes, the local strength of the vertical component of the earth's magnetic field, and to some extent on the vertical distribution of water velocities in the vicinity. Through measurements of the potential differences on two courses nearly at right angles, the drift or component velocities in these two directions are known. The vector sum or resultant of these velocities is the surface water current vector for that locality.

\section{The Development of the Geomagnetic Electrokinetograph}

The experiments which led to the development of the Electrokinetograph were begun in the autumn of I946 when the experiments of Young, Gerrard and Jevons (op.cit., 1920) were repeated using a recording potentiometer instead of a marine galvanometer. Similar results were obtained, in that the direction of water flow was correctly indicated, but the signal strength was too small for the water motion. Later work in deeper water showed an improvement of the signal strength. Beginning in the summer of 1947 experiments were performed in water ranging in depth from to to 4,000 meters to examine the effect of depth on signal strength. It was found that in water over I00 meters deep tidal and ocean currents were measurable with acceptable reliability.

A year later the depth relationship was clarified by Stommel (I948) when he investigated the theory of the electric field induced in deep ocean currents. This study showed that the amount of shear in the flow and the proportionate thickness of moving water to the total depth determines the signal strength correspondence. In that the flow in the open sea is generally greatest at the surface and there is a vast body of highly conducting, relatively quiet water between the levels of most vigorous flow and the bottom, the Electrokinetograph finds its most favorable environment on the open sea. In shoal water the principal currents may be tidal and extend uniformly from the surface to within a short distance of the bottom. Thus, except for the water saturating the bottom materials, the quiet conducting layer is thin or absent and the electric circuit is closed mainly through the higher resistance of the sea bed. This causes a serious reduction of the signal strength received by moving apparatus. Even so, it is possible to determine the water motion with some accuracy by making sets of observations in the same locality both under way and with the cable and electrodes at rest on the bottom.

By spring of 1948 instrumentation of the electromagnetic method had been developed to essentially its present form. Through the interest of Floyd M. Soule, Oceanographer of the International Ice Patrol, an Electrokinetograph was installed on the U.S.C.G. Cutter Evergreen for the I948 Ice Patrol Season; [Soule, Carter and Cheney (in press)]. The results showed sufficient promise for the instrument to be carried during the I 949 season, [Soule (in preparation)], and the practice may be continued. The results of comparisons of the currents observed electromagnetically with those inferred from the dynamic topography are discussed in section IV.

Earlier versions of the Electrokinetograph have been installed temporarily on R. V. Balanus and R. V. Atlantis of the Woods Hole Oceanographic Institution, and on the U. S. Navy Hydrographic Office oceanographic vessel U.S.S. Rehoboth (AGS-50). The latest model Electrokinetograph is at present undergoing exhaustive sea trials on $\mathrm{R}$. V. Atlantis and several different towing systems are being tested. Altogether the electromagnetic method has been used at sea about 24 months during the past 4 years, and observations have been obtained in the hachured areas of figure $\mathrm{I}$. 


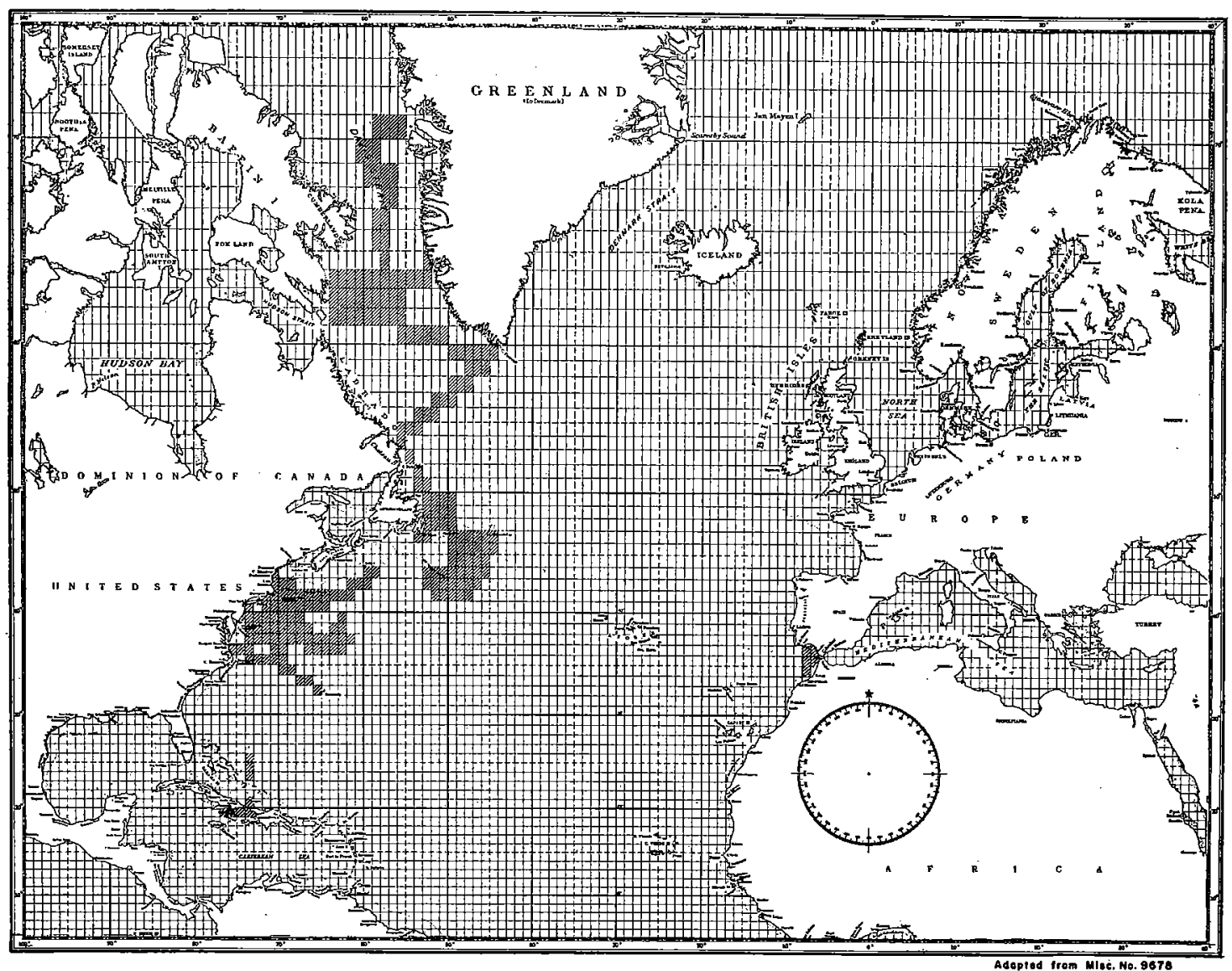

Fig. $x$. The areas in which the Geomagnetic Electrokinetograph has been used to observe ocean currents. One or more sections have been made in some part of each of the one-degree areas hachured. The ships on which the instrument was temporarily installed are: R. V. Atlantis and R. V. Balanus, W.H.O.I., U.S.C.G. Cutter Evergreen 295, U.S.S. Rehoboth AGS-50. Approximately I 5,0co miles have been covered in a total observing time of about 2,000 hours. 


\section{PHYSICAL PRINCIPLES OF THE ELECTROMAGNETIC METHOD}

Sea water contains an abundance of highly dissociated salts which make it an electrolyte of high conductivity. It is to be expected that the motion of an electrolyte through a magnetic field will produce electromagnetic effects similar to those well known for moving solid conductors. In moving electrolytes, as in solid conducting materials, the vector properties of electromagnetic effects are determined by the kinematic and external magnetic vectors rather than the geometrical configuration of the bodies, which, in both instances, restricts the measurable results but not the basic phenomena.

The motional magnetic fields of oppositely charged ions in an electrolyte moving with a velocity $\mathbf{v}$ will interact with an extensive magnetic field at rest and of intensity $\mathbf{H}$ to separate charges systematically within the electrolyte and set up in it an electric field of intensity $\mathbf{E}$ fully determined by the vector cross product

$$
\mathrm{E}=\mathbf{v} \times \mathbf{H}
$$

The direction of $\mathbf{E}$ is perpendicular to the plane determined by $\mathbf{v}$ and $\mathbf{H}$, and $\mathbf{E}$ is positively directed in the sense of rotation of a right-hand screw turned from $\mathbf{v}$ toward $\mathbf{H}$ through the smaller of the angles between them. The electric field intensity, $\mathbf{E}$, is equal to the negative gradient of the potential. Thus, the steepest gradient of the motional potential will be everywhere colinear with $\mathbf{E}$ and positively directed (plus to minus) in the same sense.

From equation (III-I) it can be said that a knowledge of $\mathbf{v}$ and $\mathbf{H}$ uniquely determines $\mathbf{E}$. In the oceanographic case $\mathbf{v}$ is the unknown. A knowledge of $\mathbf{E}$, from measurements of component potential differences, $\Delta V_{s}$, in the sea ${ }^{2}$, and a knowledge of $\mathbf{H}$ from published ${ }^{3}$ data, permits $\mathbf{v}$ to be found.

In that the oceans are approximately $I / I 000$ as deep as they are wide the most significant motions within them are horizontal. If measurements of $\Delta V_{s}$ are restricted to the horizontal plane the intensity of a horizontal component of $\mathbf{E}$ is indicated by each measurement, and with a knowledge of $\mathrm{H}_{\mathrm{z}}$, the vertical component of the magnetic field, a horizontal component of $\mathbf{v}$ is uniquely determined. To examine this more closely;

$$
v_{x} \mathbf{H}=\left|\begin{array}{ccc}
i & j & \mathbf{k} \\
v_{x} & v_{y} & v_{z} \\
H_{x} & H_{y} & H_{z}
\end{array}\right|
$$

and the components of $\mathrm{E}$ are in a coordinate system arbitrarily set so that $\mathrm{x}$ is magnetic east, y magnetic north, $\mathrm{z}$ up; $\mathrm{H}_{\mathrm{x}}=\mathrm{O}$.

$$
\left\{\begin{array}{l}
E_{x} \\
E_{y} \\
E_{z}
\end{array}\right\}=\left\{\begin{array}{l}
v_{y} H_{z}-v_{z} H_{y} \\
v_{z} H_{x}-v_{x} H_{z} \\
v_{x} H_{y}-v_{y} H_{x}
\end{array}\right\}
$$

$2 \mathrm{~V}$ is a scalar, but measured between two points $s$ apart a quantity $\Delta V_{s}$ is found having bath direction and magnitude. $\Delta V_{s}$ may be written $\nabla V$ when the components $\left(\Delta V_{s x i}+\Delta V_{s y} j\right)$ are known and composed. Similar notation will be used for $\Delta \phi_{\mathrm{s}}$ and $s$ itself.

3 The aspects of the earth's magnetic field at sea were surveyed mainly by the "Carnegie" during the years I909-I929 and the "Galilee" in the years 1905-1908. The combined observational errors and the present accumulated secular change of the main magnetic field of the earth represented in these observations, and collected on $H$. O. magnetic charts I700, I701, I702, I703, I704 and 1705, do not exceed Io millioersteds and are probably less than 5 millioersteds at most points at sea according to E. H. Vestine (personal communication). (For details see Vestine [1947, 1948]. More general information on geomagnetism is presented by Fleming [1939] and Chapman and Bartels [1940].) 
Since $v_{z}=0$ at the surface and bottom of the sea, and is probably small even in zones of sinking and upwelling, it is permissible to consider the special case for $\mathrm{v}$, the component in the horizontal plane $\left(v_{x} \mathbf{i}+v_{y} j\right)$, as determined from measurements of $\left(\Delta \mathrm{V}_{\mathrm{sx}} \mathrm{i}+\Delta \mathrm{V}_{\mathrm{sy}} \mathrm{j}\right)$ and a knowledge of $\mathrm{H}$ and its components, thus

composing $v_{x} \mathbf{i}$ and $v_{y} \mathbf{j}$

$$
\left\{\begin{array}{l}
\mathrm{v}_{\mathrm{x}}=-\mathrm{E}_{\mathrm{y}} / \mathrm{H}_{\mathrm{z}} \\
\mathrm{v}_{\mathrm{y}}=\mathrm{E}_{\mathrm{x}} / \mathrm{H}_{\mathrm{z}}
\end{array}\right\} \equiv\left\{\begin{array}{l}
\frac{\Delta \mathrm{V}_{\mathrm{sy}} / \mathrm{H}_{\mathrm{z}}}{\Delta \underline{\mathrm{V}}_{\mathrm{sx}} / \mathrm{H}_{\mathrm{z}}}
\end{array}\right\}
$$

$$
\left(v_{x} \mathbf{i}+v_{y} \mathbf{j}\right)=v=\left(-\underline{\Delta V_{s y}} \mathbf{i}+\underline{\Delta V_{s x}} \mathbf{j}\right) / H_{z}=\frac{\nabla V}{H_{z}}
$$

As only $\mathrm{H}_{\mathrm{z}}$ appears in equation (III-5) for measurements of the horizontal velocity of the sea, the $\mathrm{x}$ and $\mathrm{y}$ coordinates may be rotated around the $z$ coordinate in any convenient direction, usually so as to lie parallel to the directions $s_{\mathrm{x}}$ and $\mathrm{s}_{\mathrm{y}}$ of measurement. If these directions are measured with respect to the circles of either true or magnetic azimuth the direction of $\mathbf{v}$ is also known with respect to either of the same systems. The direction of $\mathbf{v}$ is horizontal and determined as a vector by

$$
\mathbf{v} \times \mathrm{H}_{\mathrm{z}}=-\nabla \mathrm{V}^{\prime}
$$

Measurements at sea show that $\Delta V_{S}{ }^{\prime(4)}$ is less than the motional electromotive force $\mathrm{Emf}_{\mathrm{s}}$ expected from a velocity $\mathbf{v}$ determined by independent means. This defect in magnitude arises from the less-than-perfect conductivity of the sea and the sea bed which restricts the flow of electric current in response to the motional Emf throughout the velocity field. The measuring apparatus, in motion through the magnetic field, has a motional Emf ${ }_{s}^{\prime}$ induced in it which is precisely equal to $\mathrm{Emf}_{s}$ induced in the moving sea. The equivalent circuit is shown in figure 2 wherein, $R+\overline{\sum_{0}} r$ is small compared with $r_{s}, \underline{\operatorname{Emf}_{s}}{ }^{\prime}=\underline{\operatorname{Emf}_{s}}$, and $\phi_{\mathrm{o}}-\phi_{\mathrm{s}}=\underline{\Delta \phi_{\mathrm{s}}}$

4 Primes will denote instrumental quantities.

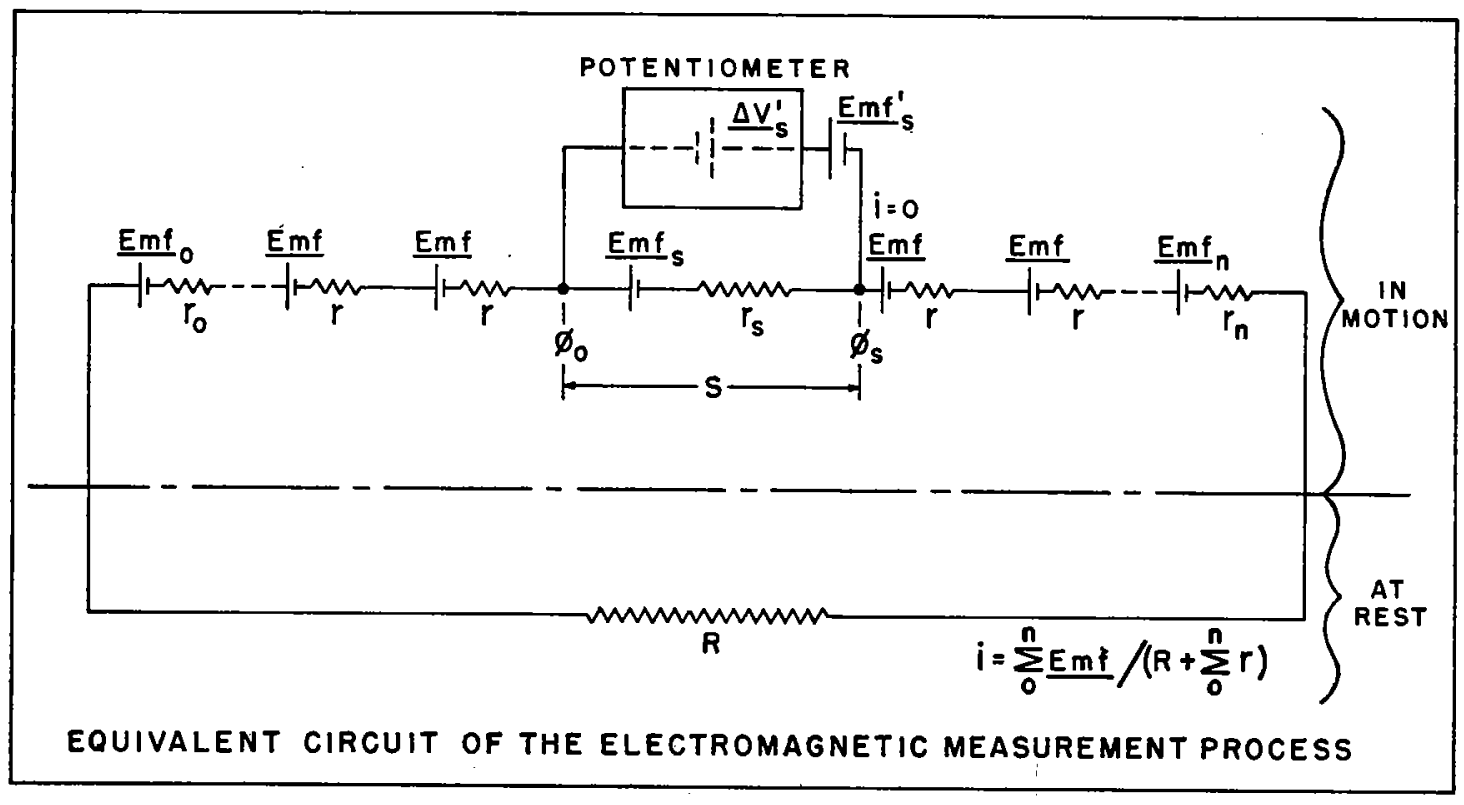

FIG. 2 
The electric current $\mathbf{i}$ flowing in the sea circuit is

$$
\mathbf{i}=\frac{\sum \operatorname{Emf}}{\mathrm{R}+\sum_{0}^{\mathrm{n}} \mathrm{r}}
$$

and the potential drop across the directed interelectrode length $\underline{s}$ is

$$
\left(\phi_{0}-\phi_{\mathrm{s}}\right)=\underline{\Delta \phi_{\mathrm{s}}}=\underline{\mathrm{Emf}} \mathrm{s}-\mathrm{ir}_{\mathrm{s}}
$$

Therefore the signal measured at the potentiometer is

$$
\underline{\Delta V_{s}^{\prime}}=\underline{E m f}_{s}^{\prime}-\underline{\Delta \phi_{s}}
$$

The value of $\Delta \phi_{\mathrm{s}}$ can be observed if the measuring apparatus is at rest so that $\mathrm{Emf}_{\mathrm{s}}{ }^{\prime}$ in the measuring apparatus is zero. At sea there is no convenient means for making measurements with the cable at rest in the earth's magnetic field, hence the value of $\Delta \phi_{s}$ must remain undetermined or be calculated from a knowledge of the velocity field.

Stommel has shown (op.cit., I948) that the induced electric potential field in any arbitrary velocity field in the deep sea is defined by

$$
\nabla^{2} \phi=\mathrm{H} \cdot \operatorname{curl} \mathrm{v}
$$

This equation expressed in finite difference form permits the application of Southwell's relaxation method (1946) to find the value of the potential everywhere in the observed velocity field. At present a number of important assumptions must be made in practicing this form of solution, consequently it does not yet serve as a routine measure for correcting or determining the accuracy of the field observations.

Stommel's discussion of the electric potential fields in the deep ocean shows that the value of $\Delta \phi_{s}$ depends directly on the ratio of the effective depth of a broad current to the total depth of water; that is, on the degree of perfection of the short circuit provided by the surrounding and subjacent water masses. His discussion also suggests that lateral extensions of the electric field adjacent to a major ocean current will cause small "fictitious" signals to be recorded. These "fictitious" signals have been studied in a preliminary way by means of the relaxation method. The potential field external to a broad but shallow ocean current is seen to die away rapidly in the horizontal direction normal to the flow but much less rapidly below the ocean current. Quantitatively these studies suggest that measurements of the surface velocity immediately adjacent to a boundary of a current may err from 3 to 5 per cent of the maximum velocity in the current due to extension of its electric field. Underneath the current and on the same level for a little distance either side these errors may be in the neighborhood of to per cent of the maximum velocity of the surface current. Exact evaluation of these errors requires a knowledge of the resistivity of the sea bed and rather detailed information concerning the velocity field in and around the ocean current. None of these data are available at present.

In the foregoing discussion, the vertical component of motion in the sea has been ruled out as negligible. While this is sufficiently true to be justified from a kinematic standpoint, it is possible for small vertical motions to have important electromagnetic effects near the magnetic equator where the vertical component of the magnetic field is 
small and the horizontal component proportionately large. Occasion has not demanded a critical analysis of the problem but it seems likely that "fictitious" signals due to vertical motions of the sea may, if these are I/rooth as strong as the horizontal motions, produce east-west signals equal in strength to those due to horizontal motions within approximately 20 miles of the magnetic equator. In order for the east-west signals due to vertical motion to be less than ro per cent of the horizontal motion signal, assuming IOO:I ratio of velocities, the site of observations would have to be removed approximately 200 miles from the magnetic equator.

It is unfortunate that both the electromagnetic method and the method of dynamic sections lose their effectiveness in the equatorial regions. However, the magnetic and geographic equators do not coincide but cross at two points, $25^{\circ} \mathrm{W}$ and $160^{\circ} \mathrm{W}$ longitude in mid-Atlantic and mid-Pacific respectively, leaving large areas where it is possible that supplementary data may be obtained by the two methods. 


\section{ON THE VALIDITY OF THE ELECTROMAGNETIC METHOD}

Reliable current measuring techniques that detect identical aspects of flow are so few it is very difficult to devise conclusive experiments which will demonstrate the validity of a new method by the process of comparison. Because of this difficulty the electromagnetic method has been tested against as many established methods as opportunity has permitted. It has also been used as a navigational aid and its effectiveness checked by Loran. The number of individual experiments is now so large that the results of the tests will be summarized in experimental classes rather than detailed. The experimental classes are as follows:

Class I - Comparison of electromagnetic observations of current with simultaneous observations made with propeller-type current meters suspended from an anchored ship,

Class II - Comparison of electromagnetic observations of current with simultaneous observations of the drift of current poles, current crosses, and dye trails,

Class III - Comparison of electromagnetic observations of current with predicted currents from tables, charts and other published sources,

Class IV - Comparison of electromagnetic observations of current with currents determined by means of a drifting ship whose drift was determined by Loran and corrected for windage by means of a chip log,

Class V-Comparison of electromagnetic measurements of current with those inferred from simultaneous observations of the dynamic topography of a large area of the sea,

Class VI - Use of the electromagnetic method to measure the current and to correct the steered heading of a ship in order to maintain a straight line of progress through a major ocean current.

\section{ThE "k" Factor}

The results of most experiments comparing the water motion observed by the electromagnetic method and other methods have been expressed in terms of the ratio $\left|\mathrm{Emf}_{\mathrm{s}}\right| / \mid \Delta \mathrm{V}_{\mathrm{s}}$ '| which is locally called the " $\mathrm{k}$ " factor. The value of $\mathrm{Emf}_{\mathrm{s}}$ used to calculate " $\mathrm{k}$ " is determined from the voltage anticipated from the water speed determined by non-electromagnetic methods, where $\mathrm{Emf}_{\mathrm{s}}=\left(\mathrm{H}_{\mathrm{z}} \mathrm{s} v\right) \times 10^{-8}$. The value of $\Delta \mathrm{V}_{\mathrm{s}}^{\prime}$ is obtained from the Electrokinetograph record of the current. The " $\mathrm{k}$ " factor would be unity if $\underline{\Delta \phi_{s}}$ were zero. Since the " $k$ " factor ratio is dimensionless it may be calculated as well from the ratio of water speeds observed by non-electromagnetic and electromagnetic methods or from other equivalent expressions.

The range of values of " $k$ " correlates with the depth of water to the extent shown in figure 3. In very shoal tidal reaches less than ro meters deep " $k$ " may vary from station to station in the range 1.5 to 15.0 and average near 10.0. On the continental shelf in depths of the order Io to IOO meters the value of " $k$ " averages less than 2.0 and seldom exceeds 3.0 in individual cases. Beyond the 150 meter isobath the value 
of " $\mathrm{k}$ " is predominantly less than $\mathrm{r} . \mathrm{IO}$ and the value $\mathrm{r} .05$ may be representative of most situations in the open ocean. Recent evidence places the average open sea value of " $k$ " at $\mathrm{I} .04$. It is thought that the correlation of " $\mathrm{k}$ " with the depth of water results from the dependence of the current regime on the depth. In areas where tidal currents

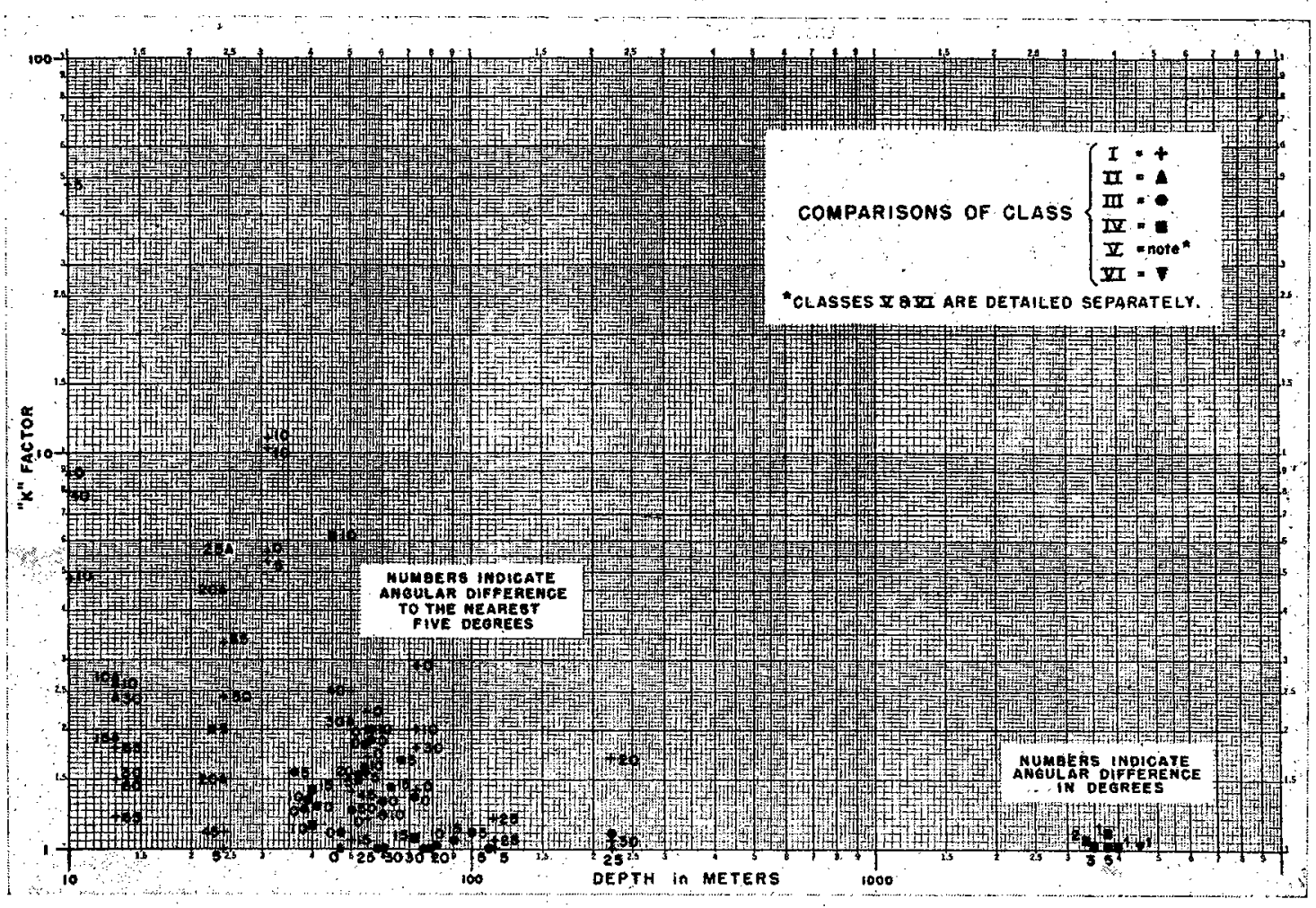

Fig. 3. The relationship between the " $k$ ". factor and depth of water determined during tests of the validity of the electromagnetic method. The decreasing scatter of " $k$ " values with increasing depth of water is thought to be due, in part, to the diminishing uniformity of water motion with depth as tidal motions give way to wind currents and predominantly oceanic circulation, and, in part, to the methods used in making the comparisons in deeper water. Beyond the Ioo meter isobath the " $\mathrm{k}$ " factor rarely departs more than 5 per cent from unity. The occasional values of " $k$ " less than unity have been plotted as reciprocals.

predominate and the flow is more or less uniform to the bottom, the bottom sediments must provide the principal short circuiting medium. Since the electrical resistance of bottom sediments is distinctly higher than that of sea water the value of $\Delta \phi_{\mathrm{s}}$ is large and $\Delta \mathrm{V}_{\mathrm{s}}^{\prime}$ is correspondingly small. On banks and the distal portions of the continental shelf the throughgoing tidal regime is progressively less dominant. Oceanic circulation reaches inward over the shelf to some extent and the fetches to the distal portions are great enough for wind driven layers to become important. Both effects introduce shear and there is a corresponding reduction of " $k$ " values. It is evident from both theory and experiment that shear will serve to reduce $\Delta \phi_{s}$ in: some instances quite as well as a thick subjacent mass of water at rest. This fact is thought to account for much of the variability of " $\mathrm{k}$ ". since in shallow mixed water shear and turbulence go together, and both may be quite variable from time to time and place to place. 
The " $k$ " factor does not take direction into account. It has been found experimentally that, while the indicated magnitude of the flow may be deficient, the indicated direction is generally more or less correctly given by the electromagnetic method. Angular errors diminish in deep water along with magnitude errors. In shoal waters comparative measurements of Class I, using current meters, reveal angular disagreements often as high as $40^{\circ}$ with occasional extremes of $55^{\circ}$ or $65^{\circ}$. Simultaneous experiments of Class I and Class II, using current poles and dye, usually show better agreement to exist in the comparisons of Class II. Class II comparisons have an average angular disagreement of $10^{\circ}$ with electromagnetic measurements and the extremes may reach $20^{\circ}$ or $30^{\circ}$. Class III comparisons with charts and tables have so far turned out better than expected in that the average angular difference of 24 observations (see table I) is slightly under $10^{\circ}$. Class IV comparisons made with drifting ships are on the average more consistent for the angular extremes have not exceeded $15^{\circ}$ even in shoal water. Deep water experiments of Class IV have shown very small angular errors despite the large probable error in determining the windage on the ship. Except for one point representing 163 navigational measurements of Class VI, the Class V and VI experiments have not been plotted on figure 3 but are detailed in succeeding figures as individual cruises.

Experiments of Class I through IV are regarded as valuable mainly in revealing the variability of the " $k$ " factor with depth and the current regime. None of them demonstrate the validity of the electromagnetic method quite as convincingly as the Class V and Class VI experiments.

\section{Discussion of Tests of the Validity of the Method}

\section{Class I Experiments - Comparison with Current Meters}

Experiments of this class were conducted with two boats; one at anchor with a propeller-type current meter over the side, and the other sailing a square course about half or three quarters of a mile on each side around the first. The sites of these experiments were all in local waters: Cape Cod Bay, Nantucket Sound, Vineyard Sound, Buzzards Bay and Block Island Sound. In all I6 stations were occupied and 31 separate measurements taken. Each measurement required about an hour and consisted of four trips around the square with the Electrokinetograph and measurement of the current with the propeller-type current meter at intervals of about ro minutes. The average of the latter was then compared with the average of the former measurements. The results are plotted in figure 3 .

\section{Class II Experiments - Comparison with Current Poles and Dye Trails}

These experiments were, in most instances, conducted simultaneously with Class I experiments but a few separate runs were made as well. In all there were 9 runs lasting about 3 hours apiece. Since surface currents were being measured electromagnetically, fluroescein dye was the principal surface tracer. Dye was dispensed on the surface either as a trail from small cloth sacks hung over the stern of the anchored boat or as a surface patch from the current poles and current crosses. When there was diasgreement between the positions of the poles and crosses and the dye patches, the dye was plotted as the more nearly correct surface current indicator. Better agreement was 
obtained between electromagnetic observations and the currents indicated by this class of experiment than with Class I. It is thought that the motion of the anchored boat interfered with both the magnitudes and directions indicated by the propellertype current meters. The results of all the Class II experiments are plotted in figure 3 .

\section{Class III Experiments - Comparison with Current Charts and Tables}

A great deal of the earlier work on the electromagnetic method consists of Class III experiments. Even now on the way out to sea from Woods Hole it is customary to run a Class III square in Vineyard Sound to make sure that the Electrokinetograph is wired properly and that everything is in working order. The present number of these test squares is unknown but the direction and speed of the current has been compared with the current tables at practically all stages of the tide. In the main channel off Tarpaulin Cove it is expected that the indicated current will lie within a few degrees of parallel with the channel and that its speed will be in fair agreement with the tabulated value if " $\mathrm{k}$ " is assumed to be 2.0.

In April of 1948 the U.S.C.G.C. Evergreen made a current section across the southern part of Georges Bank while on her way to Argentia, Newfoundland from Woods Hole. The current observations along this section of the course are charted in figure 4 and tabulated below. The rotary tides characteristic of Georges Bank are clearly revealed. The tabulated values from both the Electrokinetograph observations and from the

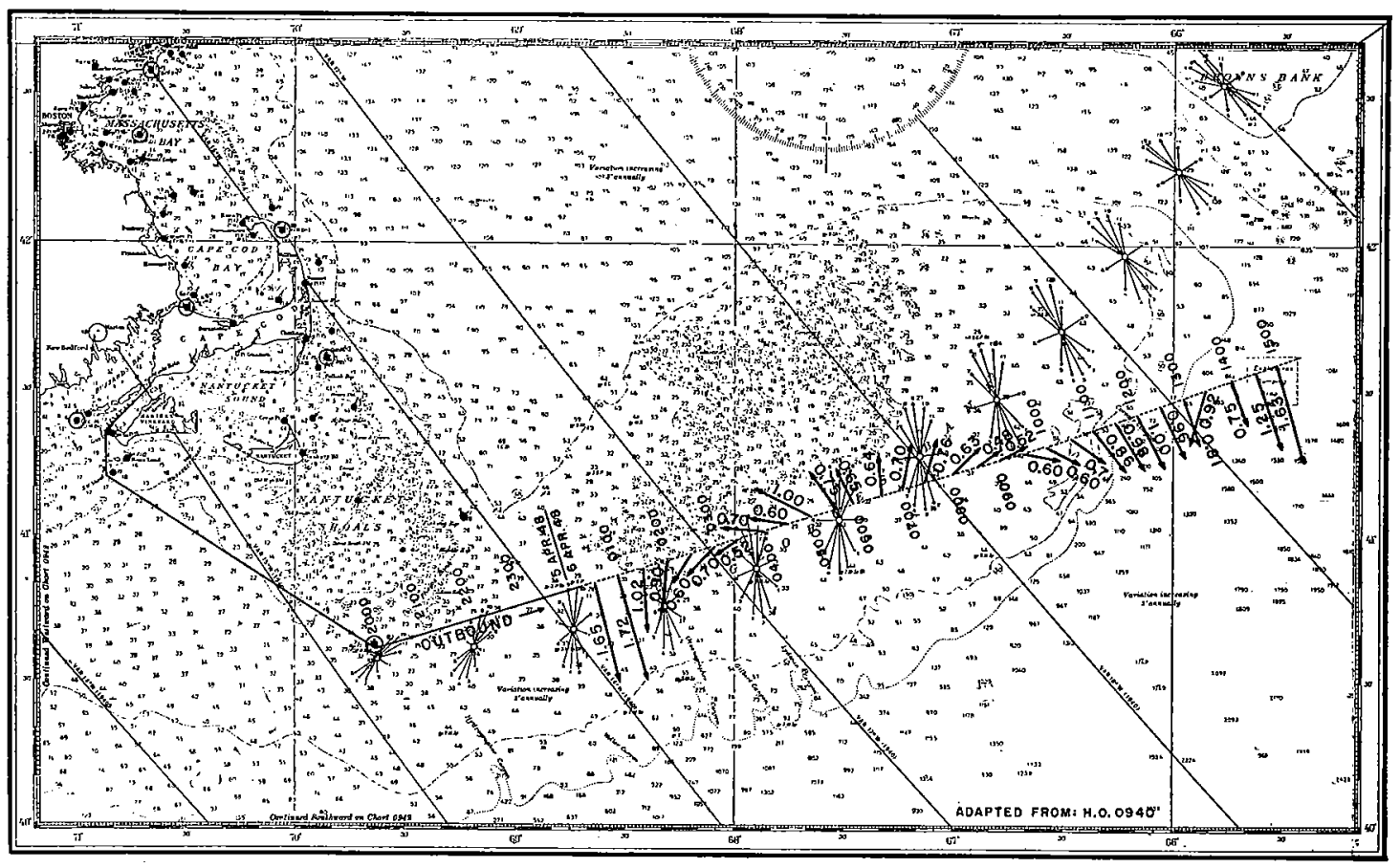

FIG. 4. The rotary tides of southern Georges Bank observed by the electromagnetic method from U.S.C.G. Cutter Evergreen while en route Argentia, Newfoundland from Woods Hole in April 1948. These observations are compared, in table I, with the tidal currents predicted by U.S.C. \& G.S. Current Tables, Atlantic Coast, $x 948$. These electromagnetic observations and all others to date by the International Ice Patrol were made with the Electrokinetograph illustrated in figure $\mathrm{I} 2 \mathrm{a}$. 
Coast \& Geodetic Survey Current Tables, Atlantic Coast, 1948 are given together with the value of " $k$ " and angular difference for each half-hourly current fix. The current magnitudes have been adjusted from the later reference station for the increasing depth of water by application of the equation of continuity. Table I shows the general agreement between the predicted current and that observed by the electromagnetic method, the changing value of " $\mathrm{k}$," and the generally minor disagreements in direction. Though the section was made in early spring the weather was sufficiently good for tidal motions to predominate over wind driven motions. Rotary tides have also been recorded many times on the continental shelf south of Block Island.

\section{Class IV Experiments - Comparison with the Drift of a Ship}

The experiments of Class IV number only 4 to date. These are plotted in detail in figure 5. In computing the drift of the ship the current vector observed at the start of the drift was given greatest weight but earlier observations were taken into account as well if the wind moved the ship across their projections. Each drift station was made under adverse conditions of sea and wind when the ship was forced to heave to consequently the windage vectors are large. The windage vectors were measured mainly by improvised chip logs and their values may err especially in direction. Nevertheless, the small errors of closure of the vector polygons for strong currents show that the measured current when corrected crudely for the leeway of the ship is reliable enough for even rather exacting purposes. All the observations of this class were made in the Gulf Stream.

\section{Class $V$ Experiments - Comparison with the Method of Dynamic Sections}

All the experiments of this class were performed by the U. S. Coast Guard Oceanographic Unit, International Ice Patrol, under the immediate supervision of the senior oceanographer, Floyd M. Soule. The wholehearted way in which these experiments were performed has resulted in a mass of data which has as yet been studied only in small samples. The data are summarized graphically in figures $6 a, b, c, d, e, f, g$ which show the current vectors observed by the Electrokinetograph superimposed on the streamlines inferred from the dynamic topography.

In detail, the correspondence between the streamlines and Electrokinetograph vectors is only fair. Since the streamlines drawn on the dynamic topography are based on the computed normal component of flow distributed by estimate between successive stations, and the Electrokinetograph vectors represent the true geographic distribution and direction of current, differences are to be expected. Comparison of the two methods in terms of the normal component of flow through the dynamic section and the normal component of the true surface current observed by the electromagnetic method has been made in terms of differences in dynamic height. Differences were established between the dynamic heights observed at hydrographic stations and those computed from the integrated normal component of flow indicated by the Electrokinetograph. The observed differences in dynamic height obtained by the two methods show an average systematic discrepancy for I 55 comparisons in the order of 3 dynamic millimeters per average station interval of 22.3 nautical miles. This, in the latitude of observation, is equivalent to a current of about $0.7 \mathrm{~cm} / \mathrm{sec}$. There is, however, an 


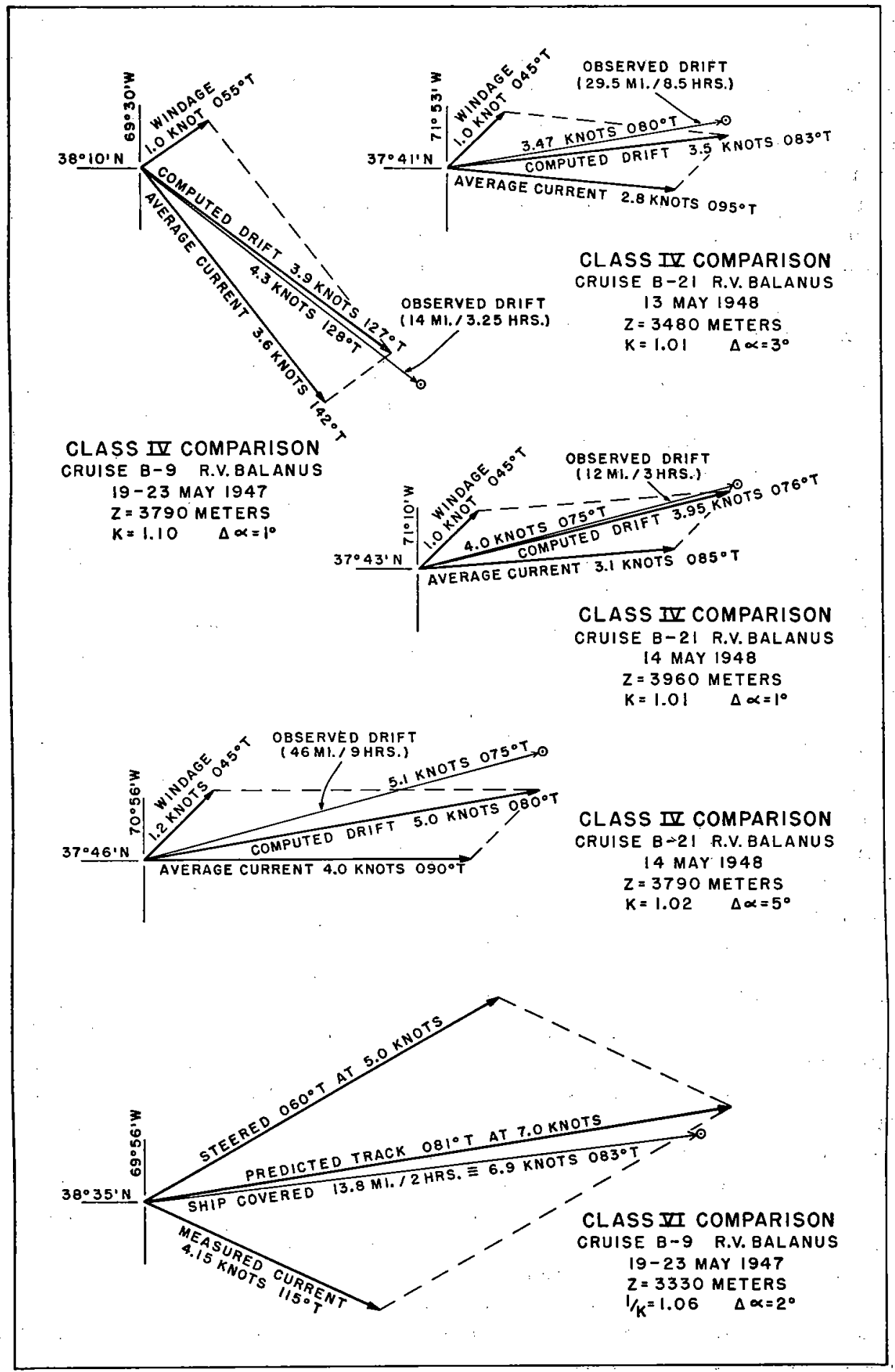

FIG. 5. The drift experiments of Class IV and the dead reckoning experiment of Class VI made by R.Y. Balanus. These show the degree of correspondence of the current indicated by the electromagnetic method and the motion of a ship observed by Loran. The Class IV experiments were made in bad weather when it was necessary to heave to, hence the windage vectors are large. All experiments plotted above were made in the Gulf Stream. The electromagnetic observations werc made with the instrument illustrated in figure $\mathrm{I} 2 \mathrm{~b}$. 
associated random difference of \pm 6.8 dynamic centimeters, equivalent to \pm I 4.8 $\mathrm{cm} / \mathrm{sec}$, between successive stations, many of which are located in tidal areas.

Present interpretation of these widely different systematic and random differences is based on an appreciation of the quite different ranges of perception of the two methods. The method of dynamic sections presumes among other things that the flow is in purely geostrophic equilibrium, in which case only the continuous tendency of motion is revealed. The electromagnetic method is thought to measure the instantaneous combination of all motions, including transients such as wind currents and tides. Since these and turbulent motions contribute a large random constituent of motion in the course of a season's observations, the existence of small systematic differences in the company of much larger random differences may be expected. Therefore, the variable discrepancy between the streamlines drawn on the dynamic topography and the current vectors observed by the electromagnetic method, shown in figures $6 a, b, c, d, e, f, g$ is probably related to the different emphasis and scope of the two methods, the inherent errors in each, and the proportion of steady and transient motions present.

\section{Class VI Experiments - Navigation Through Major Ocean Currents}

On Cruise B-9 of R. V. Balanus one Class VI experiment was performed in May 1947 and another extended experiment was performed on Cruise I59 of R. V. Atlantis in December 1949. The Balanus experiment is plotted in figure 5. The Atlantis experiment is plotted in figure 7.

On Atlantis Cruise I 59 an attempt was made to hold the ship on a segment of the line which cuts the Gulf Stream and joins Montauk Point, Long Island and Bermuda. In order to run this line the steered heading of the ship was corrected every hour by calculating the angle to which the bow should be turned upstream to correct for the drift detected by the Electrokinetograph. The angle between the steered heading and the intended course line depended on the velocity of the current and the velocity of the ship. The forward speed of the ship was measured by Pitot meter. To determine the corrected heading, a length proportional to the forward speed was used to close the vector triangle composed of the current vector and the direction of the intended course. The forward speed vector having known magnitude, and the intended course vector having known direction, the observed current vector permitted the direction of the first and the magnitude of the second to be determined.

The headings steered through the Gulf Stream made angles as great as $54^{\circ}$ with the intended course line. The Gulf Stream was crossed twice completely and twice partially during 1006 miles (1830 km) of sailing along a 430 mile $(785 \mathrm{~km})$ line segment. The geographical progress of the ship over the bottom was checked hourly by Loran. Loran data provided geographic control points for the final calculation of results, but these observations were not used in the actual performance of the steering experiment. The rules and assumptions of the experiment were as follows:

I. In order to avoid too frequent course changes with each observed fluctuation of current, the headings, correct at the beginning of each hour, were maintained throughout the hour. Thus, in increasing currents the ship was drifted downstream by an amount proportional to the increase, and in decreasing currents the ship worked upstream by an amount proportional to the decrease. In that approximately the same current systems were traversed in opposite directions, this rule is assumed to have introduced 


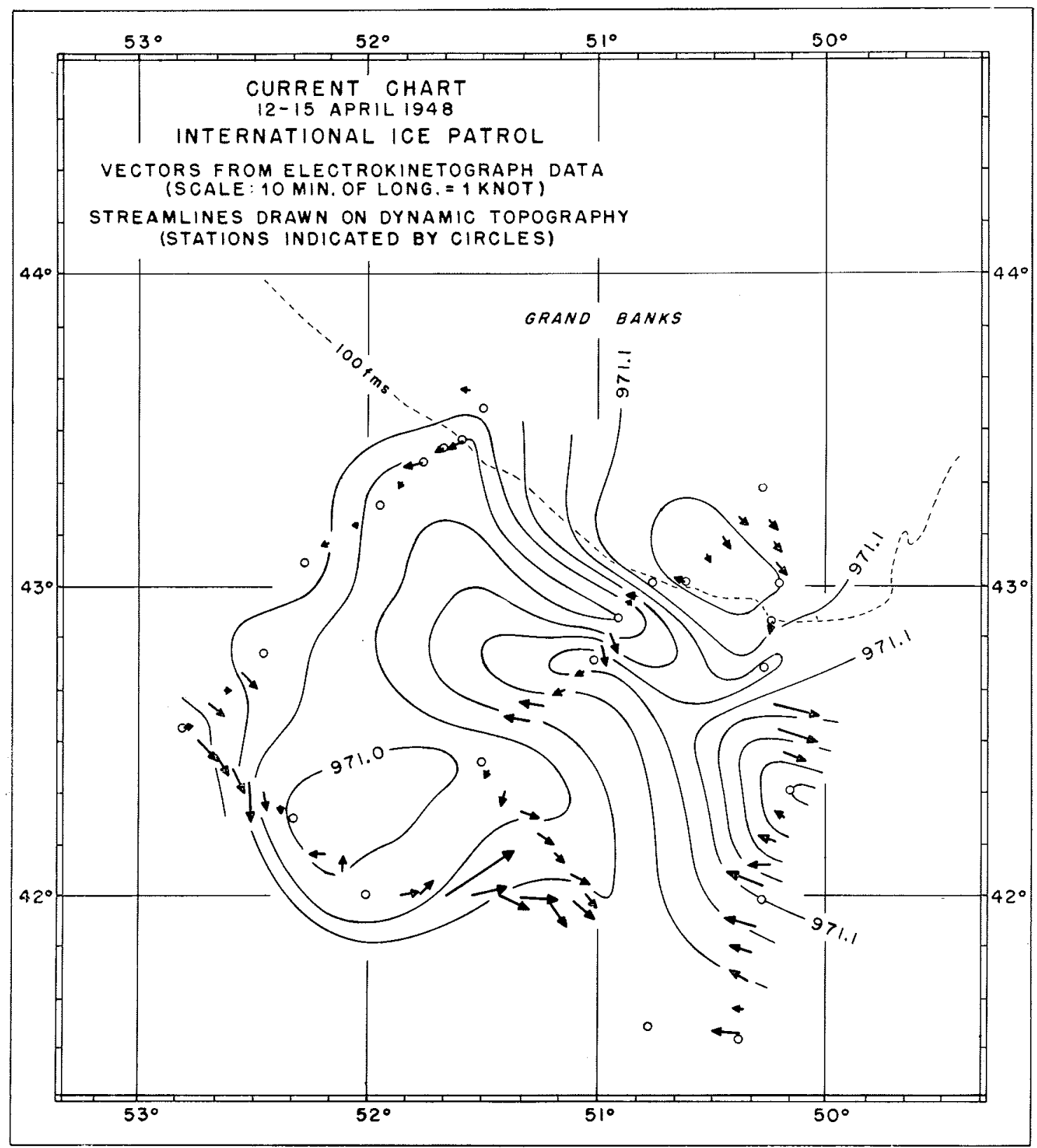

Fig. 6a. Charts of the results of simultaneous observations by the electromagnetic method and the method of dynamic sections, figures $6 \mathrm{a}$ through $6 \mathrm{~g}$. This group of charts have been drawn from data supplied by Floyd M. Soule, Oceanographer, International Ice Patrol and are reproduced with his kind permission. The current vectors shown superimposed on the dynamic topography were observed by the Electrokinetograph, shown in figure I $2 a$, operated between hydrographic stations. Preliminary studies of these comparative data show a systematic difference in the observed dynamic height and the equivalent dynamic height computed from the normal component of flow observed by the electromagnetic method, to be 3 dynamic millimeters per average station interval of 22.3 nautical miles. An associated random difference of \pm 6.8 dynamic centimeters between successive stations is possibly attributed to the location of portions of each section in tidal areas. Both tidal currents and wind currents are thought to be measurable by the electromagnetic method in addition to the steady geostrophic circulation measured by the method of dynamic sections. The correspondence of the two methods shown here may give some indication of the degree to which the steady and transient water motions are supported by dynamic topography, and the relative importance of each mode of circulation in this region. 


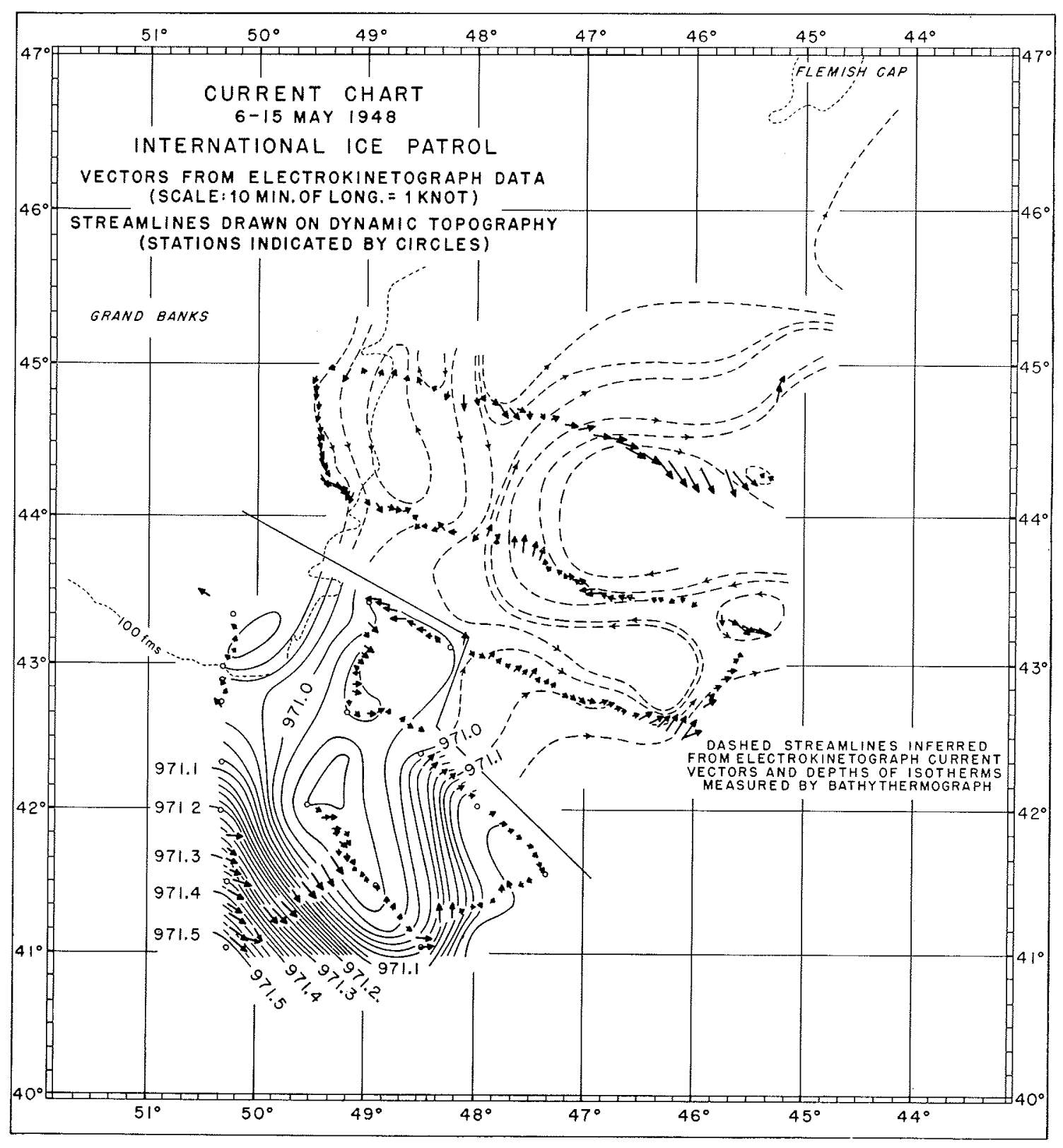

Fig. 6b 


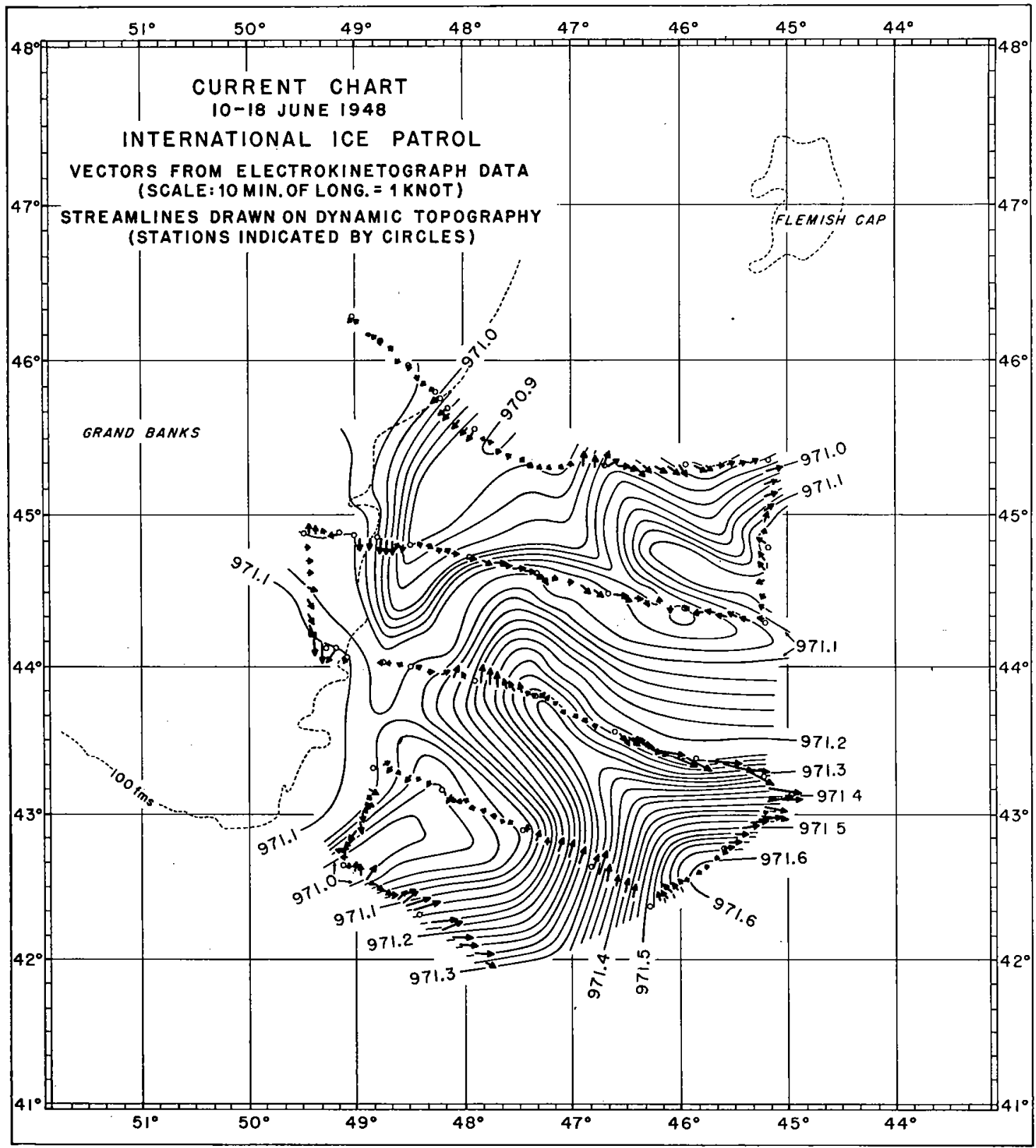

FIG. 6c 


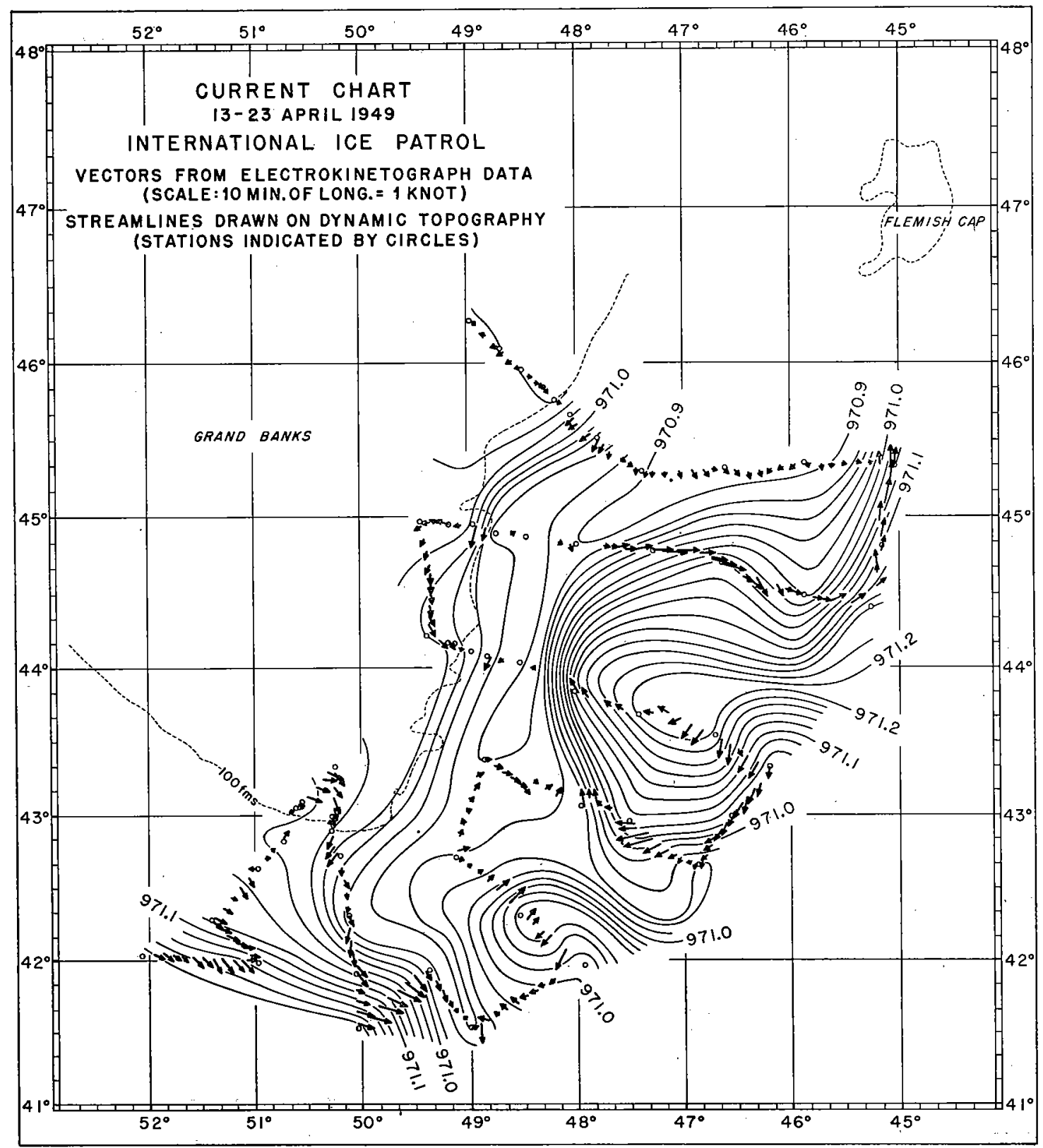

FIg. 6d 


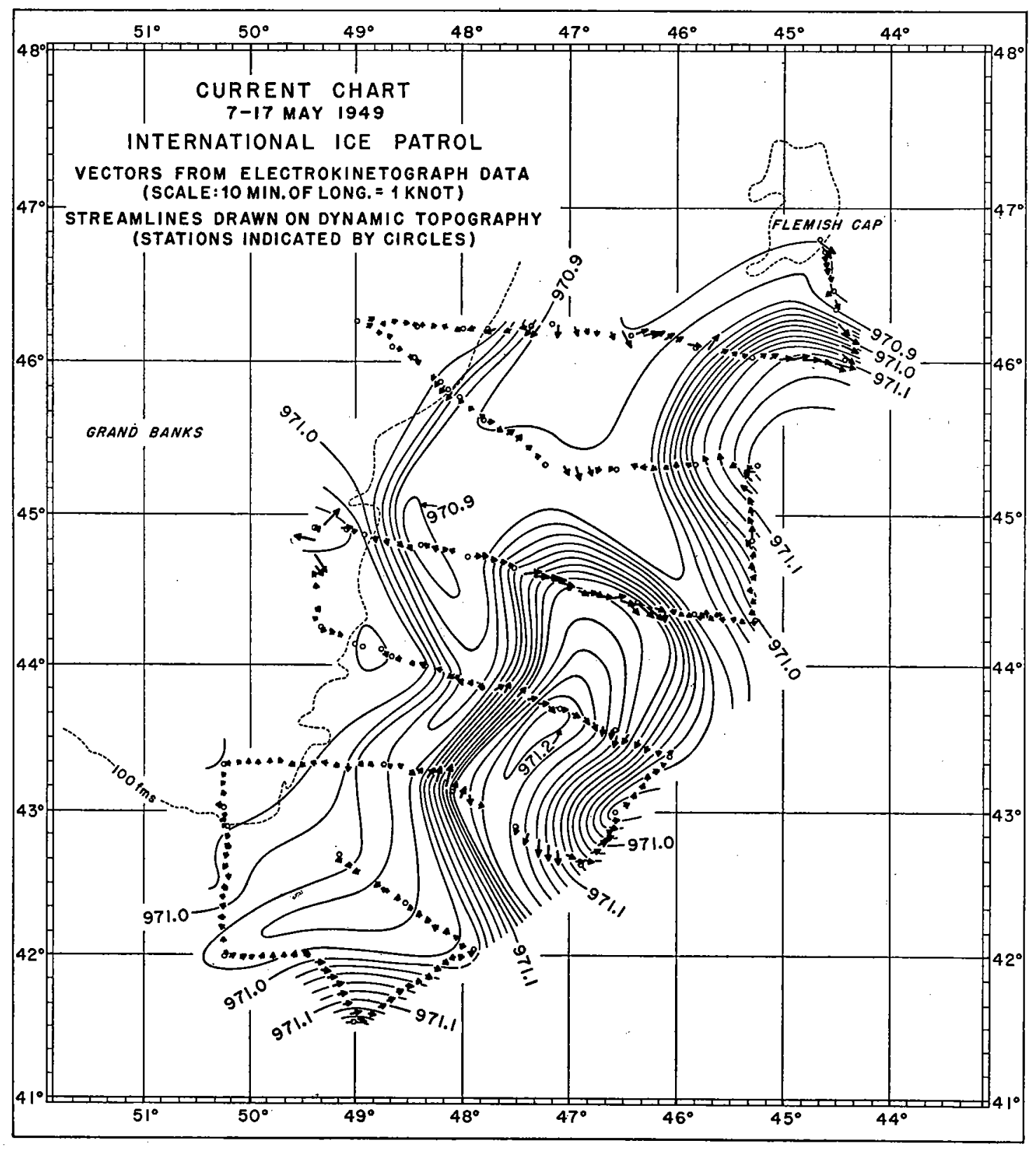

FIG. 6e 


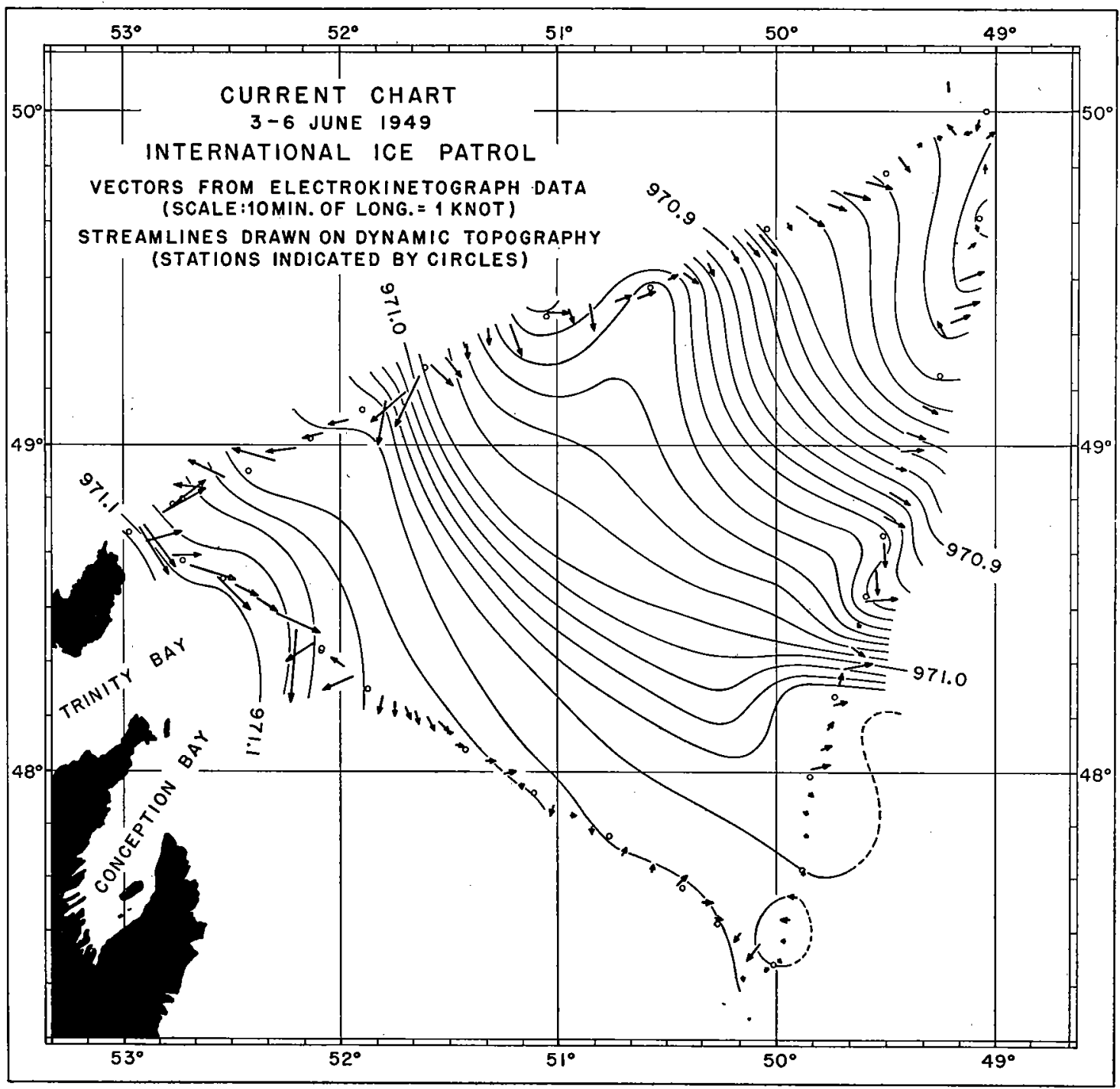

FIg. $6 f$ 


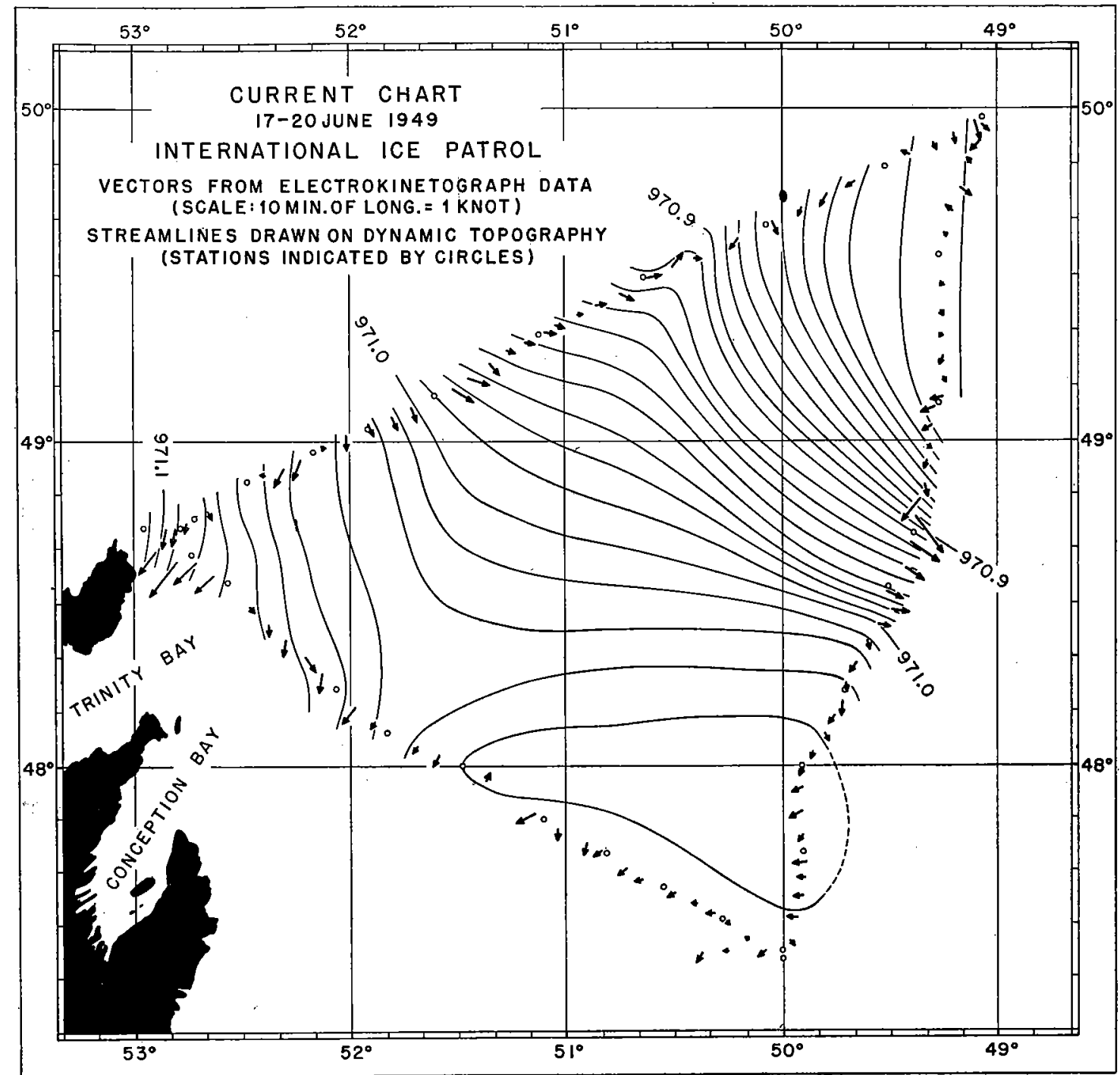

Fig. 6g

no important systematic errors over the whole cruise, or on corresponding legs in opposite directions, but to have contributed to the random error in the final result.

2. Windage introduces an experimental error in the geographic data obtained by Loran but not in the oceanographic data of the experiment. Wind will drift the ship geographically but only change the direction in which the submerged cable and electrodes are towed. The direction of the interelectrode length differs from the steered heading by $\arctan =D / C_{s}$, where $D$ is the rate of lateral drift due to windage, and $C_{s}$ is the ship's speed through the water in the direction steered. Consequently, wind drift is observed in combination with the measured current principally as a small error in direction. Gales from the northeast and north caused considerable geographic drift and eventually forced the ship to heave to for 24 and 47 hours respectively. In order to 
render the experimental data homogeneous it was necessary to counteract the effects of wind by adjustment of the dead reckoning results and the geographic results to terms of only the observed current: and ship's velocity.

3. A " $k$ " factor of unity was used in all calculations of current at sea in order that a characteristic deep water " $k$ " factor might be determined.

The greatest geographic departure from the intended line was 8.3 miles (15.1 km) due to windage. The average geographic departure from the intended line, excluding windage, was $\pm \mathrm{I} .6$ miles $( \pm 2.8 \mathrm{~km})$. At the end of the experiment the ship passed her initial position at an effective geographic distance of $\mathrm{I} .8$ miles $(3.3 \mathrm{~km})$ down stream. By dead reckoning of the total drift measured by the electromagnetic method the ship passed her initial position at an effective distance of 52.2 miles: (95.2. $\mathrm{km}$ ) upstream. In that this amount of net progress was made in a direction at right angles to the intended line and the ship closed the course geographically on the opposite side of the intended line, the total drift must have been the sum of the observed drift and the error of closure, 54.0 miles $(98.5 \mathrm{~km})$. On the assumption that " $\mathrm{k}$ " was unity the electromagnetic method detected $95.2 / 98.5$ or 96.7 per cent of the true drift. The correct net drift would have been obtained if " $\mathrm{k}$ " had been assumed to be $98.5 / 95.2$ or 1.04 . The probable error of this result can be estimated from the ratio of the average geographic departure

FIG. 7. The Class VI navigation experiment performed on Cruise I 59 R.V. Atlantis, 8-2I December 1949. The solid line joining points is in effect the course the ship would have sailed in still water. Had the ship been steered on a constant heading the average current would have drifted the ship northeast of the intended line over a course similar to the reflection at the intended line of the course sailed to compensate the measured currents. The unconnected points close to the intended line are Loran fixes showing the positions actually reached. Loran' fixes were used to check the results of the experiment but were not used in its performance. " The data for navigation were obtained entirely from the ship's gyro compass, the Pitot meter and the Electrokinetographi illustrated in figure I2c.

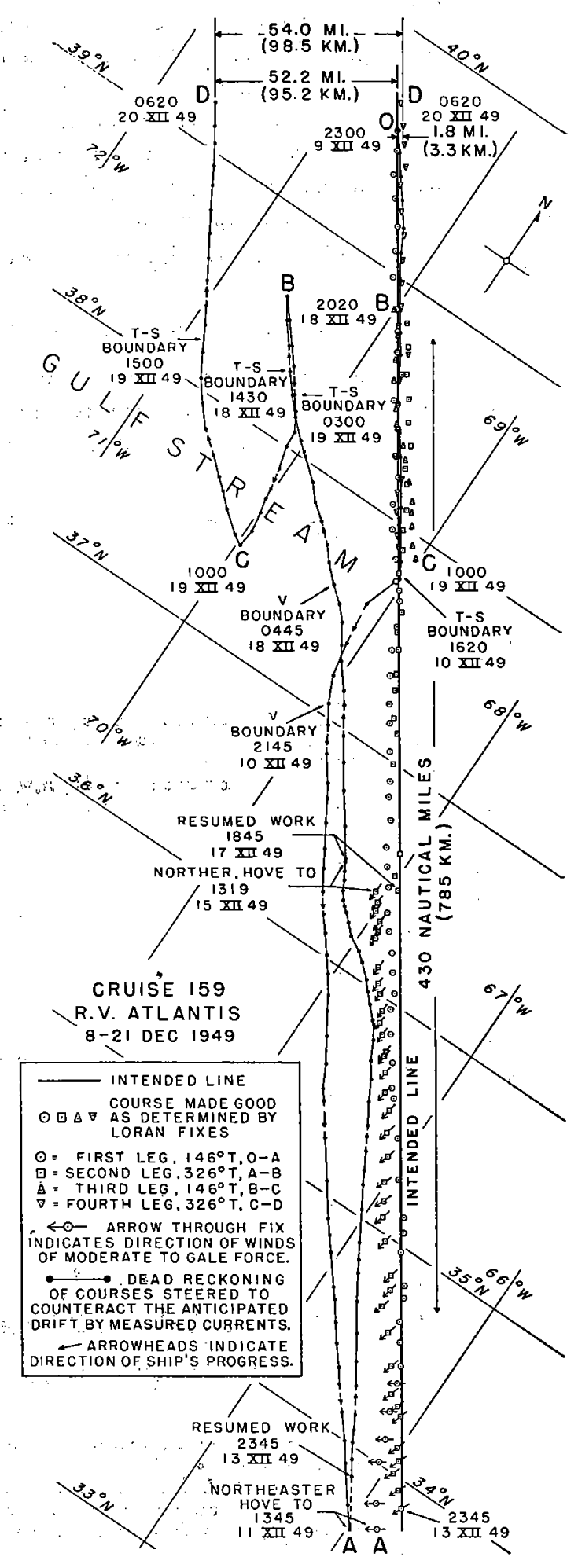


from the intended line, $\pm 2.8 \mathrm{~km}$, to the total drift, $98.5 \mathrm{~km}$, in which case " $\mathrm{k}$ " $=1.04$ \pm 0.03 . This value is in good agreement with the average of four Class IV determinations made earlier in the same general vicinity, but the scatter of these values is I.OI to I.IO. It is presumed, therefore, that the raw data from these deep water measurements are, on the average, in error less than io per cent, and that if the deep water average, I.04, has sufficiently general significance to be regularly applied to correct the systematic $\Delta \phi_{\mathrm{s}}$ error of current observations, the random errors remaining may be estimated provisionally in the order of 5 per cent.

\section{Some Oceanographic Data Derived from the Tests of the Method}

The most conspicuous feature of the Electrokinetograph traces made along sections entering the Gulf Stream is the very abrupt increase of velocity (100\% in $3-5 \mathrm{~km}$ ) regularly observed to coincide with the T-S boundary between slope water and Gulf

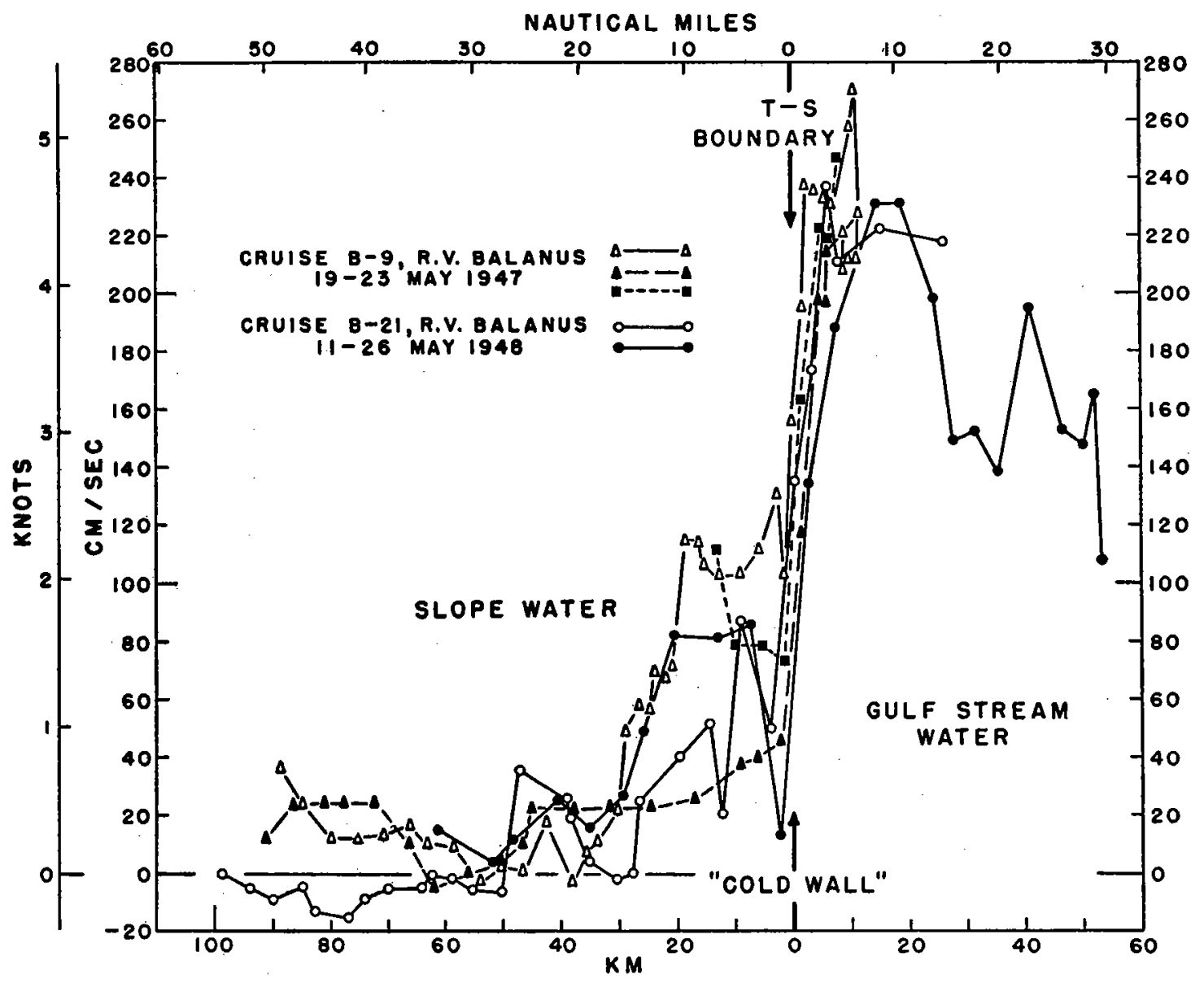

FIc. 8. A composite surface velocity section taken along lines normal to the "cold wall" of the Gulf Stream from observations between latitudes $37^{\circ}$ to $39^{\circ} \mathrm{N}$, longitudes $67^{\circ}$ to $74^{\circ} \mathrm{W}$. These observations show the entrainment of slope water by the Gulf Stream and the abrupt transition of velocity at the T-S boundary separating the two water masses. The entrainment current has been found ordinarily to be about $30 \mathrm{~km}$ wide. The Electrokinetograph traces regularly show an increasing vigor and scale of turbulence in proportion to the increasing velocity toward the Gulf Stream. 
Stream water. On Electrokinetograph cruises the T-S boundary has in general been observed with the Salinity-Temperature-Depth Recorder having the detecting element mounted on the hull so as to sample at a depth of one or two meters below the surface, which is also the electrode depth. The same correlation of velocity and temperature change has been established with the Bathythermograph, though with less precision because of the confusion of the surface trace and the interval between lowerings. The Bathythermograph sections south of Cape Cod through the "cold wall" indicate a slope of the isothermal planes in the order of $\mathrm{I}: 30$ which suggests that the velocity boundary may have a similar slope.

The surface velocity profiles through the T-S boundary at the continental edge of the Gulf Stream are given in figure 8 representing data from Balanus cruises B-9; I9-23 May I947, and B-2 I ; I I-2I May I948 toward Bermuda from Cape Cod and Cape May respectively. These velocity profiles show the existence of an entrainment current of slope water on the continental side of the Gulf Stream. The entrainment current begins roughly 30 kilometers from the $\mathrm{T}-\mathrm{S}$ boundary and with its generally increasing velocity toward the Gulf Stream, there are marked changes of salinity and temperature suggesting a shear zone. The configuration of the changes is often symmetrical in that a sequence of changes of temperature, salinity and velocity are repeated in reverse order as the ship moves along. The thermo-haline structure suggests that pools of Gulf Stream water are detached from the main current of the Gulf Stream. The velocity sequence suggests that the pools have eddy structure. Although central sections are not assured, the size of the eddy structures appears to range from 5 to I 5 kilometers across. Velocities as high as $150 \mathrm{~cm} / \mathrm{sec}$ have been observed near their margins. The velocity changes observed during a traverse indicate that these eddies may be moving bodily along with the Gulf Stream at about half its maximum velocity. There is seldom a reversal of direction of flow in the entrainment current although the velocities may occasionally fall near zero. The sense of rotation of most eddies in the entrainment current along the continental margin of the Gulf Stream appears, from these data, to be counterclockwise.

At the main T-S boundary of the Gulf Stream it is not uncommon for the velocities to double in strength in the space of less than 5 kilometers, reaching $250 \mathrm{~cm} / \mathrm{sec}$ without appreciable change in direction. It was not until Cruise I59 of the Atlantis that a complete section was made across and beyond the swift water into Sargasso water.

On crossing and recrossing the T-S boundary of the Gulf Stream four times in the course of two weeks during this cruise it was found that (I) the surface position of the "cold wall" changes laterally as much as 70 kilometers in 8 days, (2) that the Gulf Stream has a surface velocity boundary on the Sargasso side which permits the width of the swift surface current to be measured with some definiteness and (3) that the width of the swift band and distribution of velocities can change appreciably in the course of a week. The Gulf Stream was traversed first during Io December I949. It was found to be 68 kilometers wide measured from the T-S boundary adjacent to Slope Water to the velocity boundary on the Bermuda side. The maximum velocity $274 \mathrm{~cm} / \mathrm{sec}$ was observed 4 kilometers from the continental side. On I9 December I949 the Gulf Stream was recrossed in the opposite direction. The distance from the velocity boundary to the T-S boundary had increased to I Io kilometers and the maximum current was located Io $\mathrm{km}$ from the Bermuda side. The maximum velocity had dropped to 


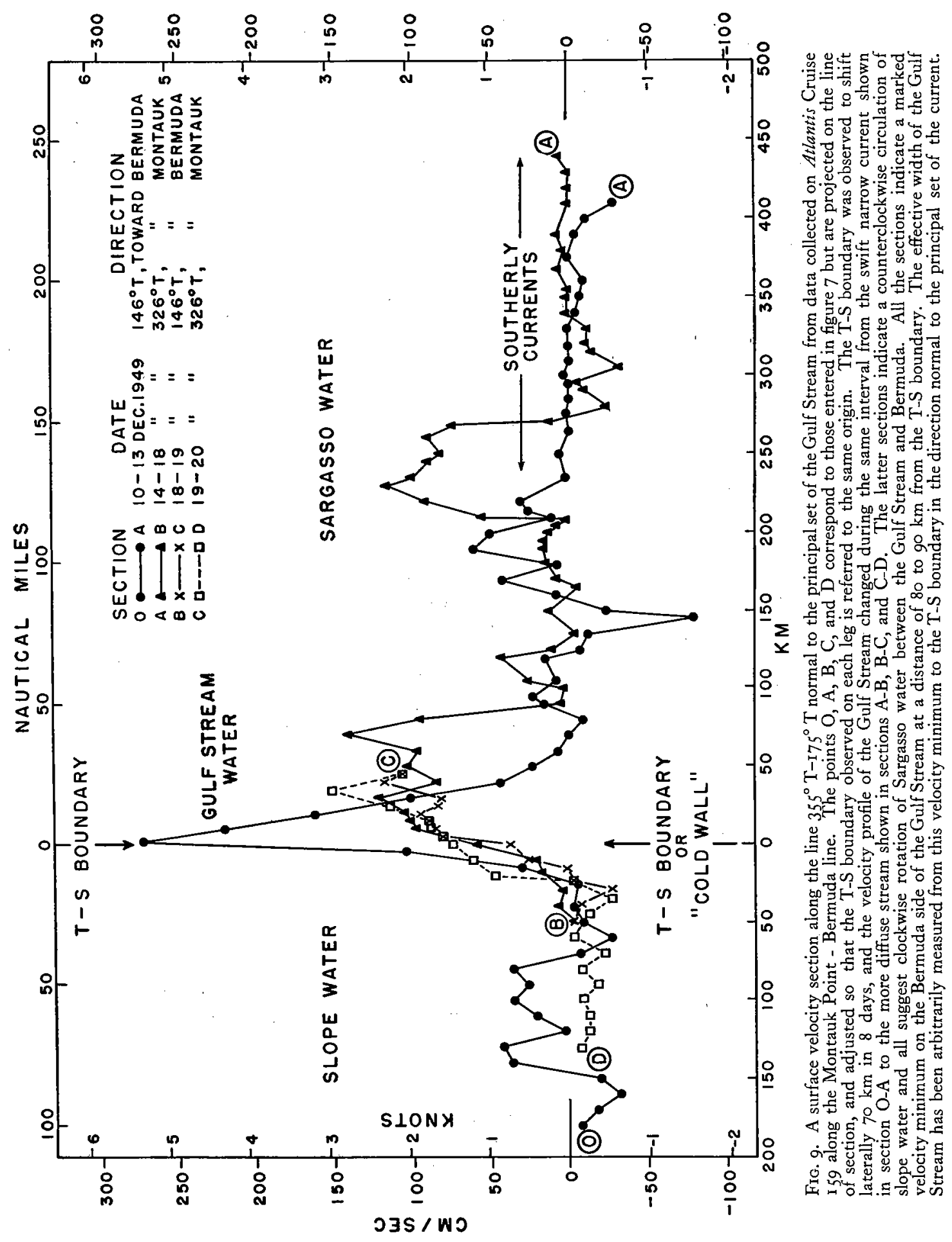


I4I $\mathrm{cm} / \mathrm{sec}$ though its geographic position was very little changed. Thus the stream had broadened and changed from being swiftest on the extreme left, to swiftest on the right, in a period of 8 days. The shorter sections made on the following two days did not cross the full width of the stream but they suggest that the swiftest water was increasing its speed and moving closer to the displaced continental boundary.

On the Sargasso side of the Gulf Stream both the outward and returning velocity sections, figure 9, indicate activity in the water resembling a large eddy perhaps 250 kilometers across rotating in a clockwise sense between the Gulf Stream and Bermuda. The second section through this region (following a northeasterly gale) shows a more marked velocity structure which seems to have its center southwest of the course line. Salinity and temperature changes in this region again coincided with velocity changes, though the greatest differences in surface salinity and temperature were only of the order of $0.1 \%$ and $0.6^{\circ} \mathrm{C}$. 


\section{PRACTICAL CONSIDERATIONS}

\section{Instrumental Sensitivity}

The electrical units of observation must be converted to velocity units. The interelectrode length $|\mathrm{s}|$ and vertical magnetic field component $\mathrm{H}_{z}$ are fixed at any given station, but $\mathrm{H}_{z}$ changes with magnetic latitude.

If " $k$ " is $I .00$, the maximum possible signal from the sea becomes

$$
\left|\underline{\Delta \mathrm{V}_{s}}{ }_{\mathrm{s}}^{\prime}\right|=\left|\underline{\mathrm{Emf}}_{\mathrm{s}}\right|=\left(\mathrm{H}_{\mathrm{z}} \mathrm{s} \text { v) }\right)_{\mathrm{ro}}-8 \text { volts }
$$

To make the conversion from millivolts to knots or $\mathrm{cm} / \mathrm{sec}$, convenient at every magnetic latitude, a choice of methods is available:

(I) One may alter, $s$, the interelectrode length as shown in figure so so that $\left|\Delta V_{s}^{\prime}\right|$ in millivolts is directly converted to knots, or $\mathrm{cm} / \mathrm{sec}$ at any magnetic latitude. Thus if the ratio $\left|\Delta V_{s}^{\prime}\right| /|v|$ is unity through suitable choice of units

$$
\left|\mathrm{H}_{z}\right| \mathrm{s}=\text { Const. }
$$

The numerical value of $\left|\mathrm{H}_{z}\right|$ in oersteds varies with magnetic latitude from 0.000 to 0.700 to the nearest tenth. If cables are made up for each Ioo millioersted increment of vertical magnetic intensity it is unnecessary to change them frequently at sea, and correction of $\Delta \mathrm{V}_{\mathrm{s}}^{\prime}$ observations to the standard isodynamic line is conveniently small. This method has been used to some extent. The value of $|s|$ at the 500 millioersted isodynamic line that will produce a signal strength of I millivolt per knot is 38.9 meters.

(2) It is still more convenient to hold $|s|$ constant at perhaps Ioo meters and vary the sensitivity but not the scale of the potentiometer recorder. If the recorder scale and strip chart are marked $(-5 \ldots \circ \ldots 5+)$ knots and $|s|$ is too meters the voltage span required for the signal on any standard isodynamic line to be directly converted to knots must be

\begin{tabular}{clll}
\multicolumn{3}{c}{ TABLE 2 } & \\
vertical magnetic intensity & sensitivity & span & range \\
$\mathrm{H}_{\mathrm{z}}=100 \times \mathrm{x} \mathrm{IO}^{-3}$ & $0.515 \mathrm{mv} / \mathrm{kn}$ & $5.15 \mathrm{mv}$. & $\pm 2.575 \mathrm{mv}$. \\
200 & $\mathrm{I} .030$ & 10.30 & \pm 5.150 \\
300 & $\mathrm{I} .545$ & 15.45 & \pm 7.725 \\
400 & 2.060 & 20.60 & \pm 10.300 \\
500 & 2.575 & 25.75 & \pm 12.875 \\
600 & 3.090 & 30.90 & \pm 15.450 \\
700 & 3.605 & 36.05 & \pm 18.025
\end{tabular}

If readings in $\mathrm{cm} / \mathrm{sec}$ are desirable and $|\mathrm{s}|$ is again $\mathrm{I} 00$ meters the scale should be redrawn to read $(-250 \ldots \circ \ldots+250) \mathrm{cm} / \mathrm{sec}$ and the values for voltage span and sensitivity changed to the following which are technically simplified and also intelligible in approximate knots.

\begin{tabular}{|c|c|}
\hline TABLE 3 & span \\
\hline $0.500 \mathrm{mv} / 50 \mathrm{~cm} / \mathrm{sec}$ & $5.00 \mathrm{mv}$ \\
\hline I. .00 & 10.00 \\
\hline I. 500 & 15.00 \\
\hline 2.000 & 20.00 \\
\hline 2.500 & 25.00 \\
\hline 3.000 & 30.00 \\
\hline 3.500 & 35.00 \\
\hline
\end{tabular}

vertical magnetic intensity
$H_{2}=100 \times 10-3$
200
300
400
500
600
700

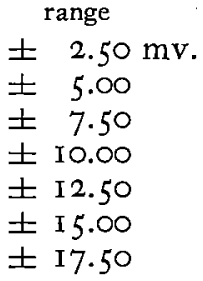

$\pm 2.50 \mathrm{mv}$.

$\pm 5.00$

\pm I0.00

$\pm 12.50$

$\pm 17.50$ 


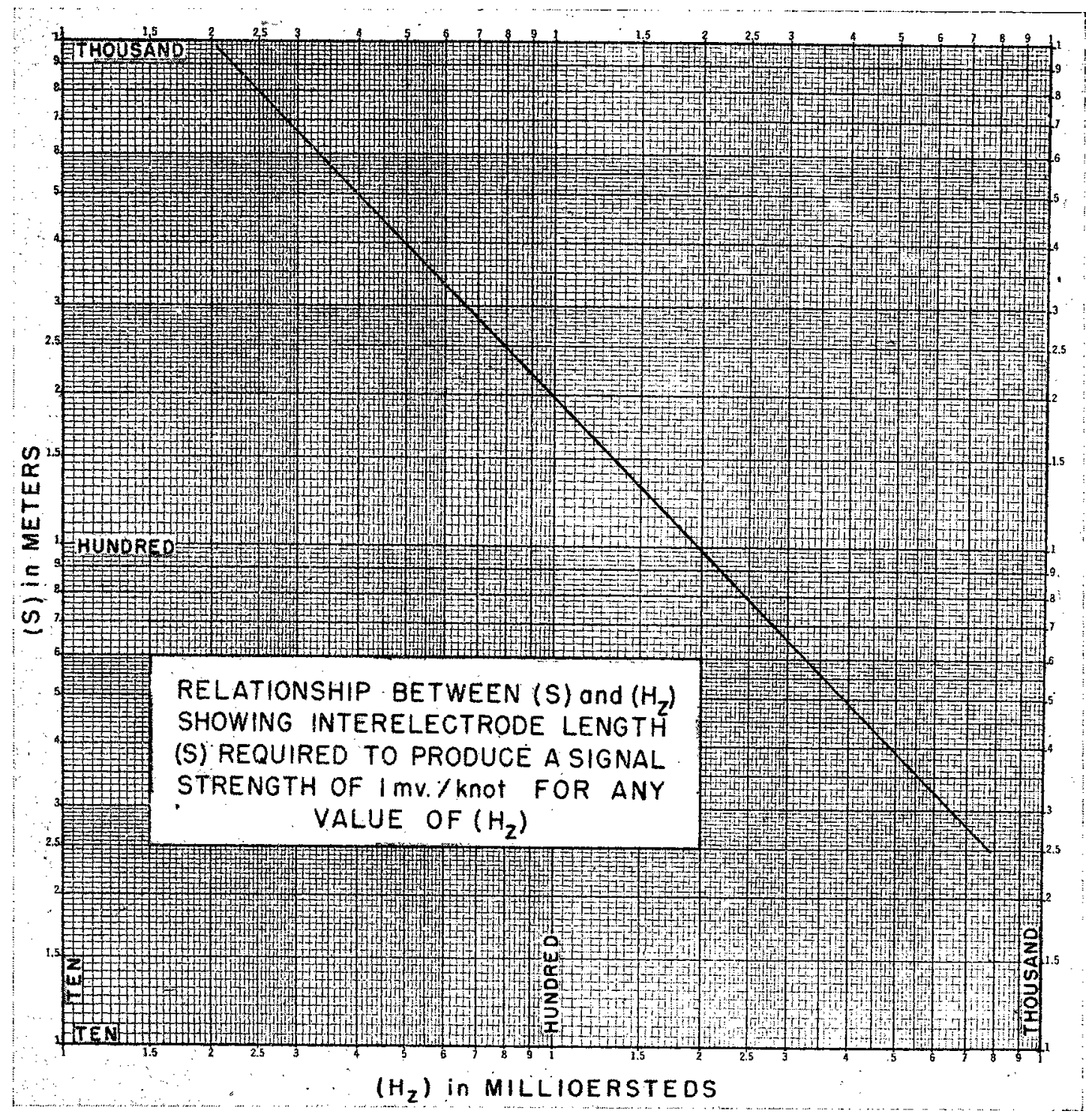

FIG. 10. One relationship for facilitating the transformation of observed voltages into velocity units by adjustment of the interelectrode length with regard for the local value of the vertical magnetic intensity. By this method, interelectrode lengths become conveniently small in high magnetic latitudes but rather large elsewhere. At the 200 millioersted isodynamic line the interelectrode length which will produce a signal strength of I millivolt per knot of current is 96.8 meters, nearly the same as the arbitrary 10o meter length chosen for the alternative method of scale switching. While no work has been done near the magnetic equator as yet, the scale switching method might be more practical in this region in that very long lengths of cable could be avoided.

Reduction of indicated data to the local standard isodynamic line remains to be done but standardized overboard equipment is employed at sea.

The chosen signal strength determines $|s|$ for any $\mathrm{H}_{z}$ and consequently the resolving power of the equipment. The systems of motion of the sea must be greater than $|s|$ across in order to be fully recorded. It is desirable to make $|s|$ large, to increase the 
signal strength, but not so large as to mask the fine structure of the sea or be physically inconvenient. Values of $|\mathrm{s}|$ ranging from 4 to 400 meters have been tried. At 4 meters the sensitivity of the recording equipment must be very high and the span of the scale excessively great to encompass the drift of zero point. At 400 meters the lengths are physically inconvenient and the time lag between ship and cable maneuvers becomes excessive. Such great interelectrode lengths have the advantage, however, of providing high signal strength, in comparison with which the drift of zero point is very small. A convenient compromise is 100 meters. With this length of cable between electrodes the signal strength is still relatively strong, zero point shifts are noticeable but not annoying, and the maneuvering time lag is short.

\section{The Wave Signal}

Even in ordinary weather at sea the wave signal picked up by surface towed electrodes broadens the recorded trace sufficiently to make the trace due to currents undesirably fuzzy. To avoid this a wave signal suppressor circuit is customarily built into the



Fig. II. The effectiveness of wave signal suppression. The wave signal suppressor condenser banks were cut into the circuit (above), and cut out (below). When cut in the circuit some time is required for the condensers to charge to the signal potential, but when they are taken out of the circuit the full signal is restored immediately. In both traces it can be seen that wave signal suppression clarifies the current signal (the deflection of the trace from zero) and the "turbulence" trace (the smaller undulations in the current trace) without entirely obliterating the very small fluctuations of potential due to waves and from which wave periods may be measured. In both panels above, time is later on the right, each vertical rule marks one minute, the heavier horizontal rules are I millivolt apart, and the middle rule is instrument zero.

Electrokinetograph deck unit. This circuit is simply a bank of capacitors in shunt across the input terminals to act as a low pass filter. The total capacitance can be altered by switches so that the value suitable to the sea conditions can be chosen. The total capacitance required ranges from 0 to 0.5 Farad. ${ }^{\mathrm{T}}$

Data are being discarded with suppression of the wave signal. The Electrokinetograph measures the orbital velocity of the wave particle motions, but the actual values

1 Certain potentiometer recorders will tolerate $2500 \mathrm{ohms}$ or more input resistance. It is possible to insert 1000 ohms of fixed or variable resistance in series with each electrode and fix the value of the wave signal suppressor capacitors so that changes of the $\mathrm{RC}$ product remain the same. 
are a function of the orientation of both the electrodes and the wave crests with respect to each other and the magnetic field of the earth. To treat this problem analytically it will be assumed that the inertia of the detecting cable between electrodes is negligible, that the waves are long-crested, that the wave length is very great compared with the interelectrode length, and that " $k$ ". is unity.

Let $A$ be the magnetic azimuth of the wave crests, $\alpha$ the magnetic azimuth of the electrode line of length, s. Let $\mathrm{H}_{\mathrm{y}}$ and $\mathrm{H}_{\mathrm{z}}$ be the horizontal and vertical components of the earth's magnetic field which will be considered confined within the yz plane (in which case $\mathrm{H}_{\mathrm{x}}$ is zero), and $\mathrm{S}_{\max }$ the magnetic azimuth of the maximum wave signal. Consider the entire length $s$ of the electrode line to move in phase with the orbital velocity $\mathrm{V}$ of the waves. The components of this orbital velocity. $\mathbf{V}=\mathbf{i u}+\mathbf{j} \mathbf{v}+\mathbf{k w}$. are

$$
\begin{aligned}
& u=a \sin \omega t \cos A \\
& v=-a \sin \omega t \sin A \\
& w=a \cos \omega t
\end{aligned}
$$

The measured signal is $\mathbf{s} \cdot \mathbf{E}$. The square of the amplitude of the measured signal is proportional to the intensity which is maximum or minimum when $\mathrm{d}(\mathrm{s} \cdot \mathbf{E}) / \mathrm{d} \alpha=0$. This occurs when

$$
\left(\mathrm{H}_{\mathrm{z}}\right)^{2} \sin 2(\alpha-\mathrm{A})=\left(\mathrm{H}_{\mathrm{y}}\right)^{2} \sin 2 \alpha
$$

Solved for $\alpha$ in terms of $A,\left(\mathrm{H}_{\mathrm{y}}\right)^{2}$ and $\left(\mathrm{H}_{\mathrm{z}}\right)^{2}$

$$
\cot 2 \alpha=-\csc 2 \mathrm{~A} \frac{\left(\mathrm{H}_{\mathrm{y}}\right)^{2}}{\left(\mathrm{H}_{z}\right)^{2}}+\cot 2 \mathrm{~A}
$$

The above result is sensitive to the magnetic dip. At the magnetic equator $\mathrm{H}_{z}=0$, consequently only the vertical component of orbital motion produces a signal. This signal is always maximum when $\alpha=90^{\circ}$ or $270^{\circ}$ regardless of the value of $\mathrm{A}$. At the magnetic poles $\mathrm{S}_{\max }=\mathrm{A}$ for the signal is maximum whenever $\mathrm{A}=\alpha$ or $\mathrm{A}+\mathrm{I} 80^{\circ}=\alpha$ since $\mathrm{H}_{\mathrm{y}}=0$ and only the horizontal component of orbital motion produces a signal. At intermediate magnetic latitudes $\mathrm{S}_{\max }=\mathrm{A}=\alpha=90^{\circ}$ or $270^{\circ}$ but when $\mathrm{A} \neq \alpha \neq 90^{\circ}$ or $270^{\circ}, \mathrm{S}_{\max } \neq \mathrm{A}$. Agreement improves as one departs from the magnetic equator but does not become perfect until arrival at one or the other magnetic pole. Through tabulation of values of $(\alpha-\mathrm{A})$ for various magnetic latitudes it is possible to make reasonably accurate measurements of wave direction when well away from the magnetic equator.

It is otherwise difficult to measure wave periods at sea and for this the Electrokinetograph is clearly helpful. If $\mathrm{A}=\alpha$ exact periods are obtained at all magnetic latitudes. If $A \neq \alpha$ but $s$ is small compared with the wave length, the orbital period will be correct provided the observing ship is not under way. If under way the periods will be given by

$$
\mathrm{T}_{\mathrm{o}}=\mathrm{T}\left(\frac{\mathrm{C}_{\mathrm{s}} \sin \theta}{\mathrm{C}_{\mathrm{w}}}\right)
$$

where $T$ is the observed wave period, $T_{o}$ the true wave period, $C_{s}$ is the velocity of the ship, $\mathrm{C}_{\mathrm{w}}$ the wave velocity (roughly determined from the uncorrected wave period) and $\theta$ is the angle between them.

The fact that the wave signal is often distorted supports the earlier opinion that there are advantages in suppressing the wave signal to clarify the signals from turbulence 
and currents. Wave signal suppression need not be so extreme as to obliterate the wave period data.

The orbital path of a water particle in a wave is not closed and its velocity in the orbit is greatest at the time of crest passage. In certain configurations of wave direction and cable orientation in regions where the magnetic dip is large, the wave signal is asymmetrically disposed around the signal due to ocean currents. ${ }^{1}$ Usually this asymmetry can be detected in the relationship of the densest part of the unsuppressed wave signal produced by the smaller waves, to the signals from the larger waves. Suppression of the wave signal reduces the asymmetry and does not permit the distinction to be made. Hence, it is well to examine the total signal from time to time, especially in rough weather. If the suppressed wave signal does not coincide with the densest part of the unsuppressed wave signal, it is desirable to measure the displacement and take it into account with the ocean current signal.

1 It has been suggested by John D. Isaacs (personal communication) that the asymmetry of the rate of change of potential in the wave signal may contribute to the drift of zero point. In high magnetic latitudes the magnitude of the potentiometer lag is greater during the passage of a crest than during the passage of a trough. This will produce a systematic asymmetry in the flow of the small electric currents through the electrodes, which, if continued watch after watch will produce a slow but persistent shift of zero point by polarization. It is believed that this is the correct explanation of an effect noted first in 1947. Since that time the effect has been reduced through the use of faster recorders, but in the light of this explanation it is clear that further reductions can be made. 


\section{INSTRUMENTATION AND SHIPBOARD PRACTICE}

In their present form both instrumentation and observational procedures are relatively straightforward. The measurements require the continuous attention of a trained observer.

The signal is collected by a two-conductor rubber-jacketed cable on which are mounted two carefully prepared Silver Silver-Chloride electrodes housed in formica guards. For surface current observations (to which this discussion is limited) this overboard cable and equipment is light enough to be handled without the aid of winches or fittings other than a boom from which to stream the cable free of the swing of the stern. The recording potentiometer on board is an industrial instrument lacking the conventional galvanometer null indicator, and therefore capable of surviving hard mechanical abuse. A gyro repeater at the recorder is a great convenience. If the ship lacks a gyro compass a magnesyn repeater can be rigged to indicate magnetic headings. Some communication system with the bridge and the helm is desirable so that courses and plans can be discussed without misunderstanding. Chart H.O. I702 should be available to give the local value of the strength of the vertical component of the earth's magnetic field. High standards of navigation should be maintained, by Loran if possible, and every available means should be used to locate the current measurements with respect to the water mass characteristics.

\section{Potentiometer Recorders and Power Supply}

The "strip chart" recording potentiometers offered by several industrial instrument makers have been found suitable for use at sea. Centered-zero scales are most useful and the voltage span or spans may be determined as suggested in the previous section. Experience shows that records of turbulence and currents can be recorded at chart speeds in the range $1 / 5$ to $1 / 2$ inch per minute with adequate detail. Wave records can be studied more easily when expanded to I inch per minute. At these rates of advance a 120-foot chart roll will last from one to five days of continuous running. The ink supply is usually sufficient to last through a week or more of continuous running. The reference batteries

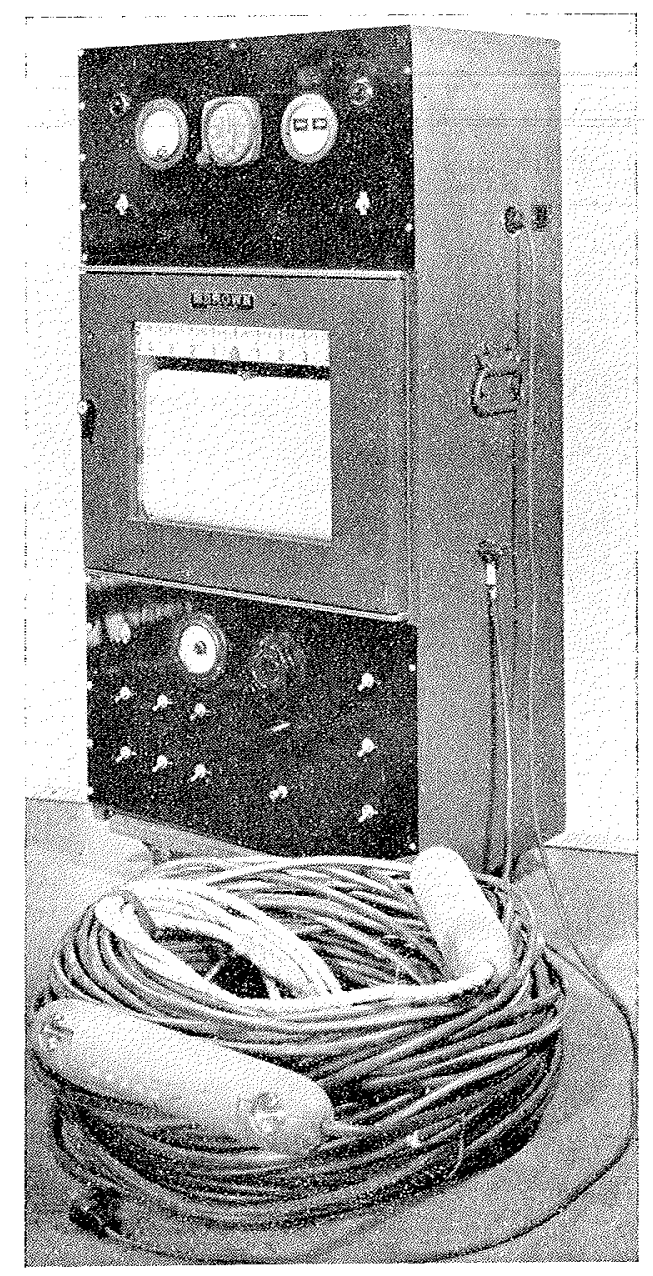

FIs. I 2a. Electrokinetograph deck unit and overboard cables howing the electrode cases and drogue. This equipment was used during the International Ice Patrol seasons 1948 and 1949. It has a Brown "Electronik" potentiometer, I 2-second pen movement, $\pm_{4}$ millivolt fixed scale span and the basic chart speed is $1 / 3$-inch per minute. The upper panel contains the power supply controls, and Magnesyn compass indicator. The lower panel contains the zero point control equipment (above), and the wave signal suppressor control switches (below). Potential-velocity transformation is facilitated by changing the interelectrode length of the cable by the re. lation given in figure IO. Figure 16 was recorded on this instrument. 
last for a month in the tropics and much longer in high latitudes and are automatically standardized against a built-in standard cell.

The speed at which the recording pen traverses the full span of the scale differs with the instrument make and design. The choice of pen traverse speed or "tracking speed" depends on the work in view. Waves require high speed pen traverse to keep pace

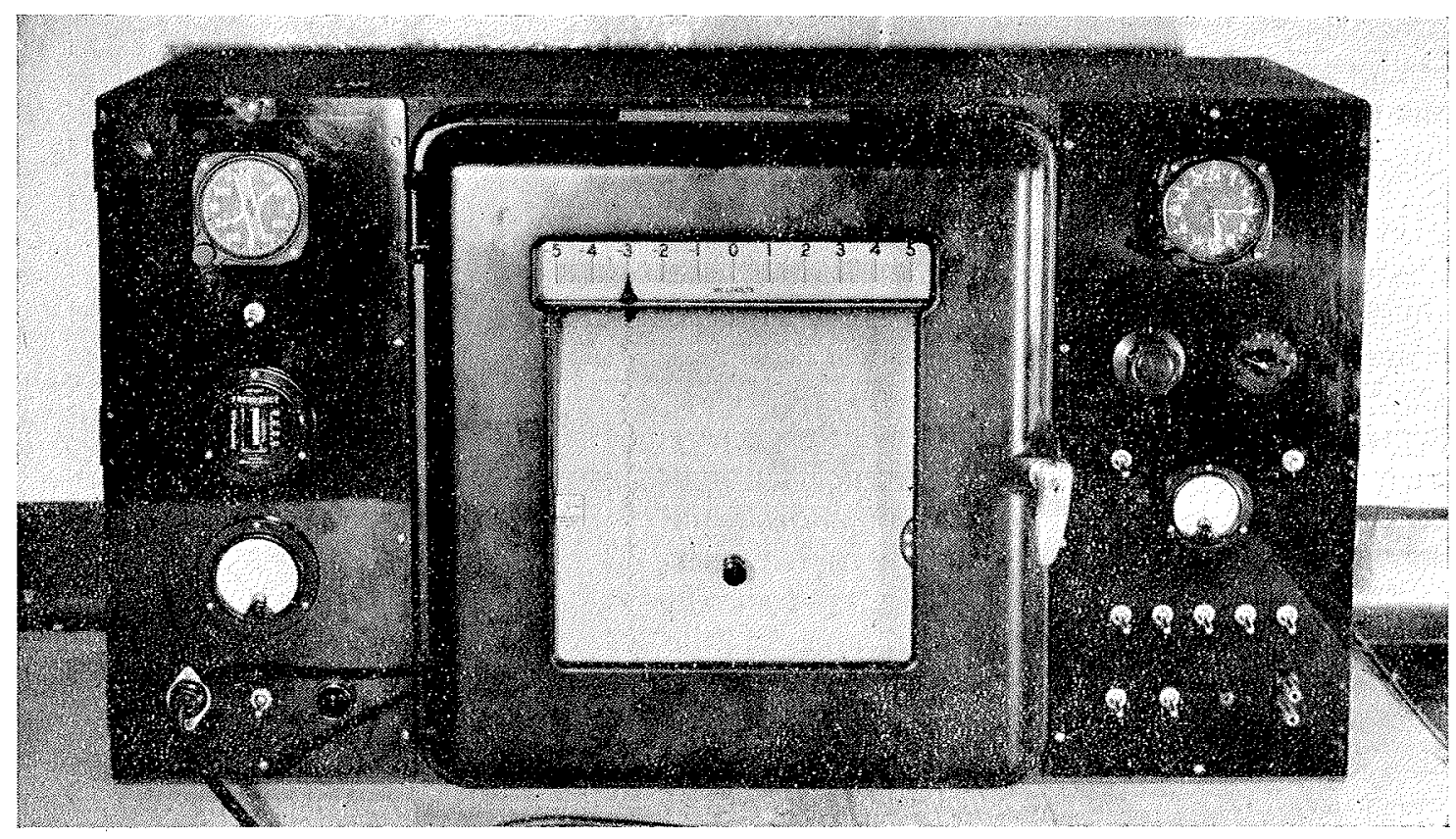

FIG. 12b. Electrokinetograph deck unit used on R.V. Balanus and U.S.S. Rehoboth AGS-50. This instrument has a Leeds \& Northrup "Speedomax" potentiometer recorder, 2-second pen movement, \pm 5 millivolt fixed scale span and the basic chart speed is 1/2-inch per minute. The left panel contains the power supply and Magnesyn compass components. The right-hand panel contains the zero point control equipment and the wave signal suppressor switches. Figure II was recorded on this instrument.

with the rapidly changing signal. Two seconds full-scale traverse ordinarily will give negligible suppression of amplitude due to pen lag. This speed will, of course, keep pace with any more slowly changing signal.

The electric power required for these instruments is usually i io volts, 60 cycles, and their power consumption is under Ioo watts. On shipboard it is necessary to isolate the power by an isolation transformer to block any possible D.C. leakage that may be present on the lines, see figure I3. The voltage and frequency of the input power should be monitored to arrest any variation of time-keeping on the strip chart, which is synchronously driven, and to assure maintenance of optimum sensitivity of the recorder amplifier, which is slightly sensitive to supply voltage. All components of the power supply on the instrument side of the isolation transformer should be insulated from the ship.

Similarly the signal input leads from the cable over the side should be shielded and insulated from the ship. Grounding is not often necessary but when it is, the safest ground is the first electrode in the cable string overboard. 


\section{Cables}

The primary function of the cable is to bring aboard a signal from the sea and cable motion from far enough astern to be unaffected by the ship itself. Ordinarily I.5 to 3 times the length of the ship is sufficient for wooden and steel hulls respectively. The cable may tow in the wake for the turbulence there is usually too small and rapid to be resolved, but it is easier on the cable and probably better practice if it is towed from the end of a boom trained well over one side. The clearance from the tow point should be sufficient to allow the cable to pass by the stern untouched even during very rapid turns. Arrangements such as a signal hoist to the end of the boom permit convenient handling of the cable both in setting and recovering it under way. The longitudinal drag on 200 meters of cable at 3 or 4 knots can be overcome without mechanical aid but at 8 knots it is usually all one man cares to hold. In paying out into the ship's wash it is only necessary to avoid kinks and to keep the cable clear of the screw. Periodic snubbing with the hands will unlay the twists from coiling down and prevent sudden strain when all the slack has gone out. Both shielded and unshielded rubber-covered cables having a breaking strength of Iooo pounds or more have been used with equal success. Though the shield in this case serves no electrical purpose it arrests slight propeller gashes, the bites of fish, and the sawing action of the cables to other instruments over the side-notably the bathythermograph - that might open the insulation over unshielded wires.

Cable connections to the recorder have been made according to the following convention for the northern magnetic hemisphere: the conductor leading to the more distant electrode is connected to the input terminal which made positive gives a right-hand deflection of the pen. This convention was adopted so that an observer facing forward with the recorder before him will see the pen on the same side of

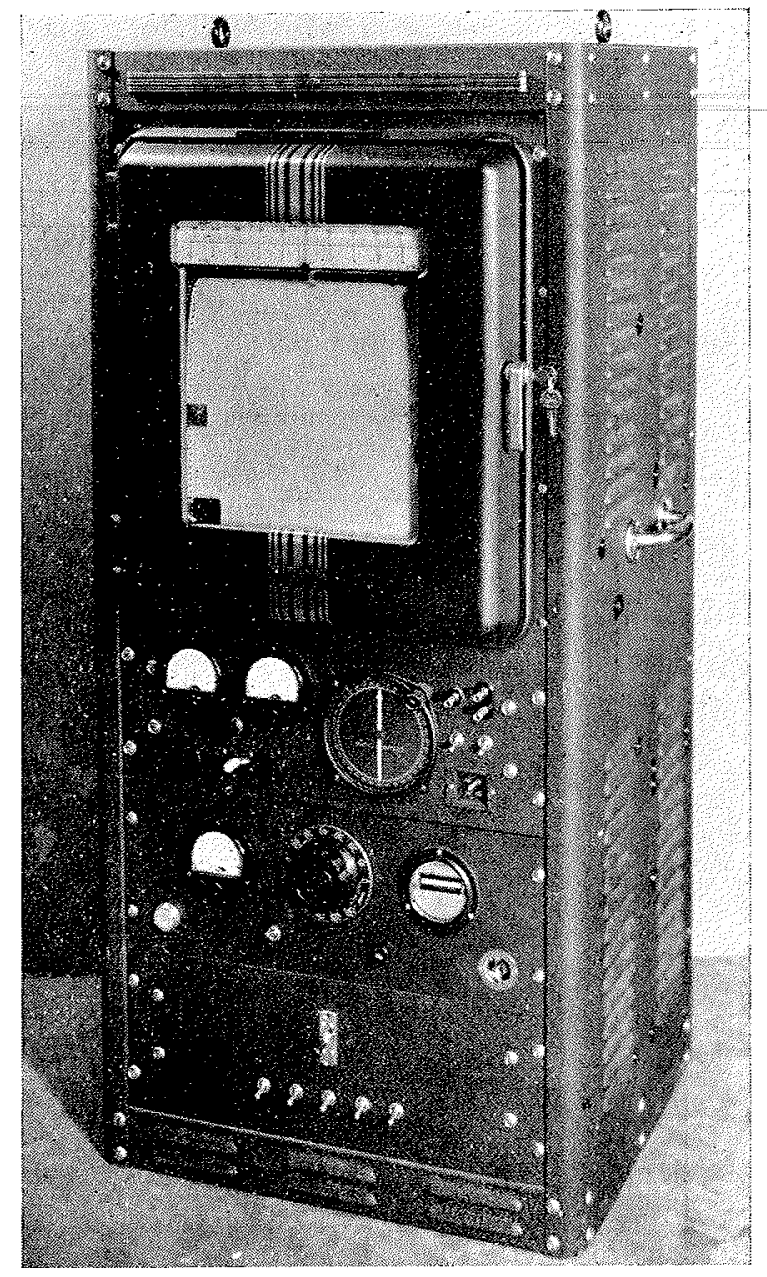

FIG. I2c. The most recent Electrokinetograph deck unit which employs scale switching rather than changes of interelectrode length to facilitate conversion of observed voltages to velocity units. The potentiometer component is a Leeds and Northrup "Speedomax" recorder having the special scales given in table 3 , a 2 -second pen-movement, and $1 / 5$-inch per minute basic chart speed. The instrument scale is calibrated in $\mathrm{cm} / \mathrm{sec}$ with knots indicated below. A port set is indicated to the left and a starboard set to the right of instrument zero at center. The scale switching knob is located inside the case above the instrument scale and it is marked in 0.1 Oersted units of vertical magnetic intensity from 0.1 to 0.7 . The lower panels contain the wave signal suppressor controls (below), fower supply controls (middle), and zero point controls and gyro repeater (above). A similar instrument was used on R.V. Atlant is for Cruises I 59 and 160. 


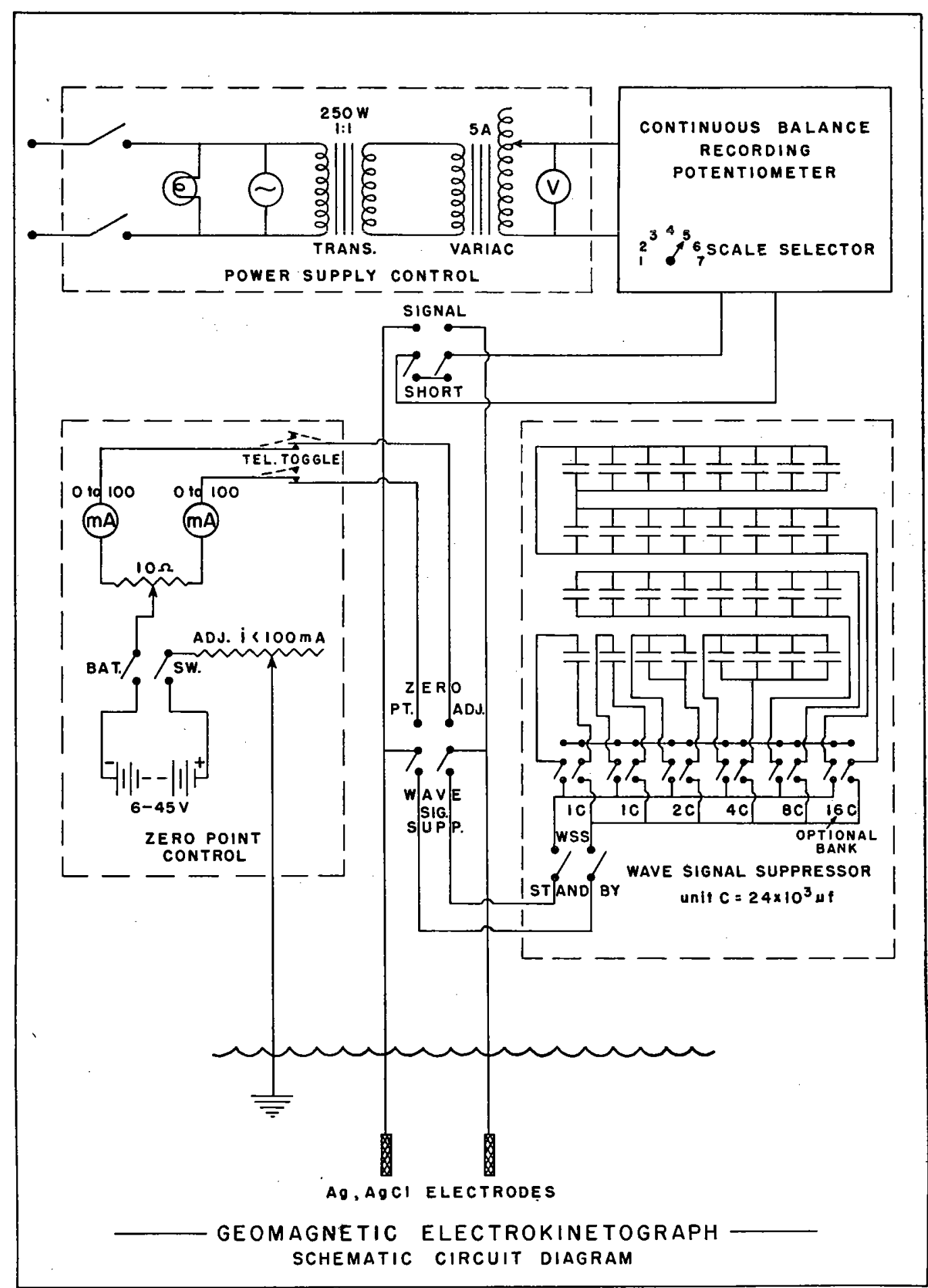

FIG. 33 
zero as the direction toward which the ship is being set. The connections must be reversed in the southern magnetic hemisphere to have the same convention apply.

\section{Electrode Pairs}

In order for the Electrokinetograph to function it is necessary that the ends of the cabled wires from the moving apparatus make good electrical contact with the sea. Of necessity this is a metal-electrolyte junction, and a source of potential. If the two electrodes required at the junctions are matched and oppose each other in the circuit their potentials will cancel. But it is very difficult to construct a pair of electrodes so similar in chemical composition and physical properties that their potentials will always cancel, even in the limited range of salinities, temperatures and pressures afforded by the oceanic environment. Despite an effort to make a uniform product in the laboratory it has been found necessary to employ chance and to construct sizeable batches of electrodes from which compensating pairs are selected by means of appropriate tests. Even the best pairs of electrodes leave something to be desired. These stubborn defects make necessary a considerable complication of the sailing and observing techniques, and postpone the possible routine uses of the electromagnetic method.

An extended series of laboratory experiments and field trials suggests that of the several common non-polarizing electrode designs the metal metal-halide, particularly silver silver-chloride and possibly calomel, electrodes are best suited to use at sea with the Electrokinetograph. These electrodes have sufficiently low electrical resistance to be used with industrial recording potentiometers and because their inherent insolubility is augmented by the common ion effect in sea water they are quite durable chemically. The silver silver-chloride electrodes are durable physically as well and they can be stored dry. They fail, however, by a little more than one order of magnitude to reach the degree of stability and reproducibility required to eliminate the zero point determination associated with use of a Ioo-meter interelectrode distance. An increase of the interelectrode distance by an order of magnitude would be very inconvenient. Lately, some improvement in both stability and reproducibility has been obtained when the members of a new batch of electrodes are allowed to stand short-circuited in a common jar of sea water for several weeks. This treatment evidently permits electrochemical reorganization of the electrode surfaces and not only reduces the potential differences at the temperature and salinity of the bath but increases the uniformity of response to changing conditions as well. Repeated tests of arbitrarily selected pairs in one batch of electrodes over a period of a month showed that improvement ceased to be significant after about the second week.

It is desirable that if $E_{1}$ and $E_{2}$ are the potentials of the two electrodes respectively,

$$
E_{1}-E_{2}=f_{1}(T, S, \phi, p, f, a, \ldots)-f_{2}(T, S, \phi, p, f, a, \ldots)=0 .
$$

where $T$ is the temperature, $S$ the salinity, $\phi$ the potential, $p$ the pressure, and $f$, and a, are flushing and airation respectively. It is also desirable that the rate of change of potential is the same in each for a given time rate of change of environmental conditions.

$$
\frac{d E_{1}}{d t}-\frac{d E_{2}}{d t}=f_{1}{ }^{\prime}\left(\frac{d T}{d t}, \frac{d S}{d t}, \frac{d \phi}{d t}, \text { etc. }\right)-f_{2}\left(\frac{d T}{d t}, \frac{d S}{d t}, \frac{d \phi}{d t}, \text { etc. }\right)=0
$$


In use at sea a pair of electrodes I00 meters apart may be exposed to temperature differences of the order of $\circ^{\circ} \cdot 3 \mathrm{C}$ and rates of change of temperature $\mathrm{dT} / \mathrm{dt}$ of twice that order per minute. Salinity gradients may be steep enough to cause $0.00 \mathrm{I} \%$ difference in the environments 100 meters apart and $\mathrm{dS} / \mathrm{dt}$ may be $0.5 \%$ per minute. Similarly $\mathrm{d} \phi / \mathrm{dt}$ may reach peak values of 50 millivolts per minute.

It has been customary to study functions $f_{1}$ and $f_{2}$ in steady state first. The temperature, $\mathrm{T}$, is changed by steps through the range $0^{\circ} \mathrm{C}$ to $30^{\circ} \mathrm{C}$, the salinity, $\mathrm{S}$, is changed by steps through the range $26 \%$ to $36 \%$. An artificial potential, $\phi$, of adjustable magnitude suddenly applied to the electrolyte causes the electrodes to polarize slightly, but they should settle down to a steady reading in less than a minute. Pressure sensitivity, $p$, is ordinarily not tested in selecting pairs for surface towing. Flushing, $f$, and aeration, a, are tested by violently stirring the electrolyte both with and without admixture of air. This ordinarily shifts the "zero point" of the electrode pair in one direction or another and the shift is reversible. The shift should not exceed o.I millivolt and should be relatively insensitive to the intensity of flushing and aeration once the electrodes have been exposed to it.

Electrode pairs that pass the steady state tests can be further tested for gradient response to the same environmental factors. Physically the gradients can be set up by isolating one electrode in a porous container immersed in the electrolyte (sea water) bath. The environment provided at the electrode in the container will lag changes made in the bath by amounts determined by the porosity and thermal conductivity of the container. A lucite cylinder plugged with glass wool at the bottom permits adjustment of porosity and maintains temperature differences of an appropriate magnitude. If the zero point of an electrode pair is shifted not more than 0.1 millivolt in response to the gradients of salinity and temperature mentioned, the pair is considered acceptable for use at sea. Potential changes, $\mathrm{d} \phi / \mathrm{dt}$, are produced by alternating $\phi$ rhythmically through $\pm 5 \mathrm{mv}$. every Io seconds. A good pair should reach $95 \%$ of their steady state reading in less than that time.

About one or two pairs of electrodes out of every dozen will pass these tests. Rejected electrodes may form acceptable pairs with electrodes from other batches. Both accepted and rejected electrodes may be stored dry in "peg board" fashion if light is excluded.

The zero point of silver silver-chloride electrodes in service can be shifted under way, if necessary, by means of the zero point control circuit shown in figure I3. This circuit may be temporarily grounded to the hull or to a piece of metal hung over the side. If the electrodes are made negative the coatings are reduced and if made positive the coatings are enriched in silver salts. Since the thickness of the silver halide coatings influences the contact potentials, the potential difference between the two electrodes can be influenced to some extent. But the electrode surfaces are severely disturbed by the zero point control circuit, consequently provision is being made to eliminate it in favor of a zero adjustment in the potentiometer recorder which will permit the zero point potential to be shifted to the center of the strip chart. Since zero point drift usually grows smaller with time, the adjustment will remove the need to disturb this process and may provide the effect of greater electrode stability.

Some increase in stability has also been obtained by decreasing the permeability of 
lagging materials around the electrodes. The zero point drift is much less sensitive to transient changes of temperature and salinity when each electrode is embedded in a cast of about 50 grams of gypsum plaster. This material ultimately dissolves and crumbles away but its properties are otherwise desirable. Both the polarization and gradient response of a coated pair is smoothed and the shifting zero point is easily followed in the course of ordinary routine. The coating lengthens the initial time required for the electrodes to be wetted, but once wetted they remain in condition for immediate service even after a period of several days in air.

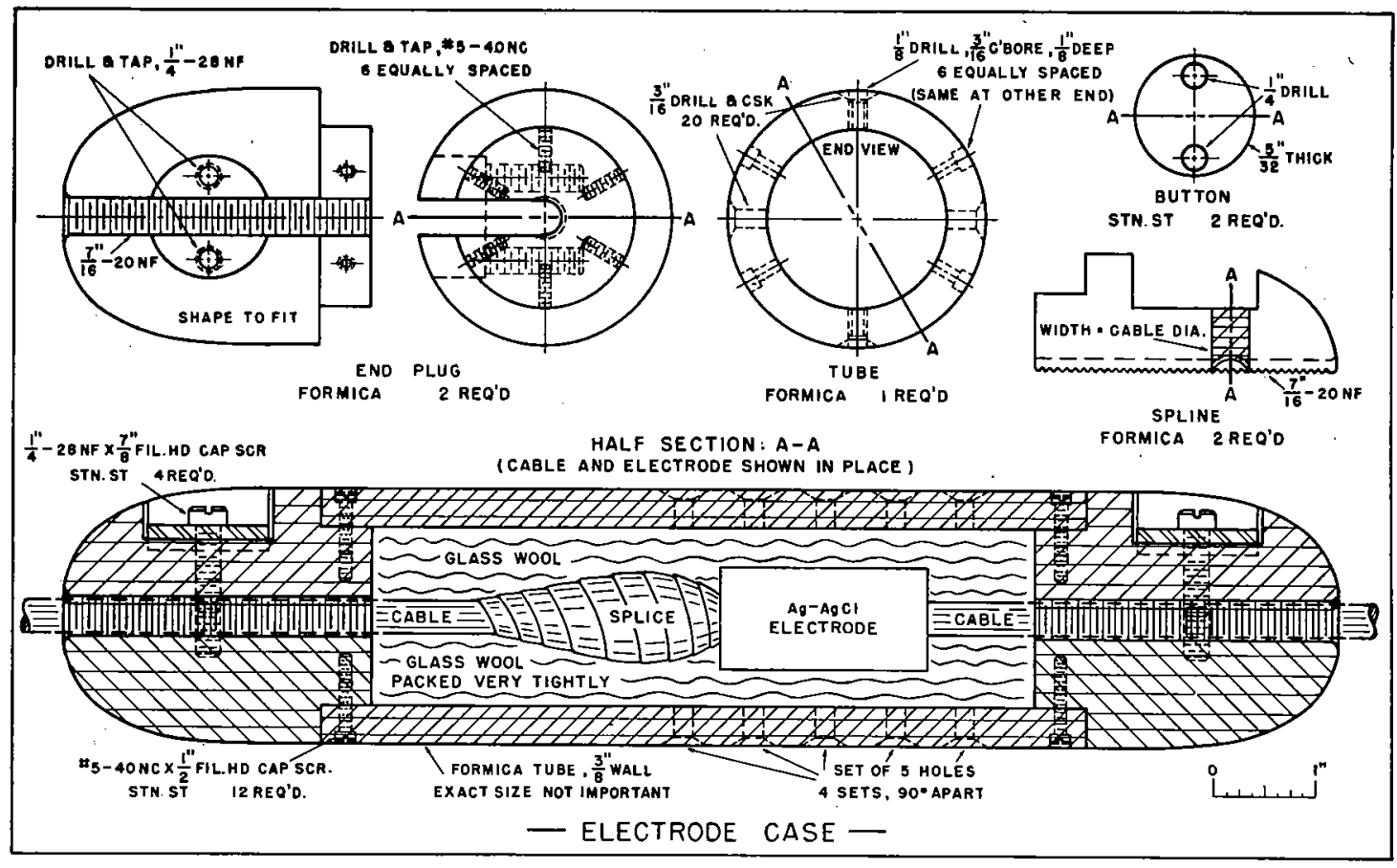

FIG. I 4

The electrode case shown in figure I4 serves not only as a guard but as a means for controlling the environments of the electrodes. It consists of a strong formica cylinder fitted with rounded end plugs that are designed to clamp the cable firmly. The after end of the last electrode should be fitted with an 18 or 2 I-thread Manila drogue about 5 meters long to keep its towing motion straight and steady. The number and size of the holes in the housing cylinder is optional. In recent instances the electrode has been mounted in the blind end of the housing and the perforations reduced to two holes at the opposite end. Similarly when the glass wool packing has been found to be too porous other lagging materials have been substituted. In general it is found that an electrode behaves best when it is nearly isolated from the sea both physically and chemically.

The non-motional potential differences of electrode pairs can be regarded as having two distinct sources; a persistent and slowly changing potential difference due to polarization in a homogeneous environment, and a thernodynamic potential change that is accounted for in terms of the theory of the reversible half-cell. The polarization po- 
tential in a homogeneous environment is ordinarily measured as the zero point and can be removed from consideration in observations of current velocity since the sign and magnitude of the effect is not altered by the angle of section through a current system. The distributions of salt concentration and temperature are usually related to the current structure and therefore their electrochemical effects cannot be distinguished from velocity signals or removed in the process of zero point determination.

\section{Electrochemical Errors of Electrodes}

There is a strong tendency in the sea for isohaline and isothermal surfaces to parallel the streamlines of flow. Study of the electrochemical effects at electrodes in response to changes of temperature and salinity suggests that the voltages recorded in crossing the boundaries of major currents and their eddies may not be entirely due to velocity changes. The signal may have a compound origin; (a) a natural origin due to the change in water velocity, and (b) an added or subtracted signal of electrochemical origin due to the T-S gradients at the boundary. To evaluate the electrochemical effects on paired electrodes, laboratory studies have been made of their behavior in gradients similar to those found at sea. For comparison, computations have been made of the theoretical magnitude of the T-S effect in terms of the theory of the one component concentration cell. of the form

$$
\mathrm{Ag}, \mathrm{AgCl}^{-}{ }_{(\mathrm{s})} ; \mathrm{Cl}_{\left(\mathrm{a}_{1}\right)} \| \mathrm{Cl}^{-}{ }_{\left(\mathrm{a}_{2}\right)} ; \mathrm{Ag}, \mathrm{AgCl}_{(\mathrm{s})}
$$

The activity coefficients $\left(a_{1}\right)$ and $\left(a_{2}\right)$ suffer change with changes of temperature and salinity in the ocean. Should simultaneous changes occur at both electrodes, concentration cell theory predicts that no change in potential difference will be observed. In practice small unpredictable changes result from the physical and chemical dissimilarity of the electrodes and corresponding differences in heat capacity and the density or distribution of their chloride ion atmospheres.

Beyond this, laboratory results show that the Temperature Coefficient of Potential is 0.00060 volts $/{ }^{\circ} \mathrm{C}$, and that the Salinity Coefficient of Potential is -0.00055 volts $/ \%$ for $\mathrm{Ag}-\mathrm{AgCl}$ electrodes. Results also show by their sign that an increase of temperature or of salinity has an effect on the signal in the same sense. The theoretical confirmation of these results is satisfactory.

The theoretical Temperature Coefficient of Potential for the range 0 to $30^{\circ} \mathrm{C}$ has been calculated and found to be -0.00059 volts $/{ }^{\circ} \mathrm{C}$. This value is in substantial agreement with the laboratory experiments with sea water. The theoretical Salinity Coefficient of Potential has been calculated for the range 26 to $36 \%$ of $\mathrm{NaCl}$ solution and is found to have an average value -0.00069 volts $/ \%$. This is in approximate agreement with laboratory experiments covering the same range of salinity in sea water. Both of the calculated coefficients agree well enough with the coefficients determined experimentally for $\mathrm{Ag}-\mathrm{AgCl}$ in sea water to indicate that the change of activity of the chloride ion in sea water is the most important factor affecting the performance of these electrodes. 
To sum up the calculated chloride ion concentration and temperature effects:

$$
\begin{aligned}
\left(0.30^{\circ} \mathrm{C} / 100 \mathrm{~m}\right) \times\left(-0.00059 \text { volts } /{ }^{\circ} \mathrm{C}\right) & =-0.000177 \text { volts } / 100 \mathrm{~m}(\mathrm{~T}) \\
(0.0075 \% & =-0.0000052 \mathrm{volts} / 100 \mathrm{~m}(\mathrm{~S}) \\
\text { the T-S sum is }) \times(-0.00069 \text { volts } / \%) & -0.000182 \text { volts } / 100 \mathrm{~m} .
\end{aligned}
$$

This is the spurious signal generated by electrochemical effects at the electrodes in the most extreme gradients of temperature and salinity found along the continental margin of the Gulf Stream. The relative error in current velocity which this signal produces depends on the signal strength. If $\mathrm{H}_{2}$ is 500 millioersteds and $\mathrm{s}$ is 100 meters the signal generated by $150 \mathrm{~cm} / \mathrm{sec}$ (about 3 knots) of current is 7500 microvolts. The relative error introduced by the electrochemical signal is (I $82 / 7500$ ) and the per cent error $2.4 \%$. This is equivalent to an absolute error in velocity of $3.6 \mathrm{~cm} / \mathrm{sec}$ which in this instance is directed against the water current signal so that the measured velocity is too low by this amount.

It is also too low by the amount of the $\Delta \phi_{\mathrm{s}}$ signal associated with the motional electric potential generated in the Gulf Stream. This produces a "fictitious" water current signal having the equivalent velocity of from 2 to $4 \mathrm{~cm} / \mathrm{sec}$. The two erroneous signals are additive in this instance. Thus the true water current speed is about 6 or $8 \mathrm{~cm} / \mathrm{sec}$ greater than the uncorrected data indicate. Even so, the entrainment current of water adjacent to the Gulf Stream is evidently real and the corrected velocity profile through it is not radically changed. These corrections presume that the isotherms and isohalines parallel the streamlines of water motion and that the electric currents generated in the velocity field are normal to the streamlines of flow.

In the neighborhood of slower ocean currents where the thermo-haline gradients are presumably less steep, both erroneous signals are reduced. If the reduction is proportional to the flow the sum of the thermo-haline signal and the $\Delta \phi_{\mathrm{s}}$ signal is expected to remain under $5 \%$ of the theoretical signal for a given velocity in the open sea. In or near river effluents or other points where water of markedly different temperature and salinity is flowing, the thermo-haline gradients may be so steep that the electrochemical effects become serious. In these situations the measured velocity on either side of the boundary will not be in error due to thermo-haline effects, but during transition from one water mass to the other velocities may be exaggerated or suppressed. Whether exaggeration or suppression occurs depends on the sign of the electrochemical effect as it enters the algebraic sum with the motional signal. An increase of temperature and/or salinity along the course produces a spurious velocity signal directed to the right. Entry from the left in to a velocity field in the northern magnetic hemisphere also produces a spurious velocity signal directed to the right of the course. It is possible for these effects to almost cancel each other under certain circumstances.

\section{The Sailings}

The courses the observing ship is called upon to steer for Electrokinetograph observations are determined by the necessity; (a) that potentials shall be measured on at least two headings at right angles if possible, (b) that at least once an hour the electrodes shall be reversed end for end to determine the "zero point" and (c) that as little of the ship's time as possible be wasted in progressing toward her destination.

(a) The measured voltage vectors on two headings are components of the directed 
potential difference, $\Delta \mathrm{V}_{s}^{\prime}$, from which, $\mathrm{v}$, the water velocity vector is determined. The velocity vector, $v$, lies $90^{\circ}$ to the right of $\Delta V_{\mathrm{s}}^{\prime}$ in the northern magnetic hemisphere.

(b) The "zero point" is the position the recorder pen occupies in the absence of an external signal from the motion of the sea, and from which the values of the measured voltage vectors take their numerical origin. It differs from the instrumental zero by the amount of the inequality of the potentials of the electrodes connected in opposition to each other in the circuit. This inequality varies with the environmental changes in the ocean and the gradients of these changes, as suggested by equations (VI-I) and (VI-2) and their discussion. To evaluate the potential difference $E_{2}-E_{1}$ at sea the awkward technique of reversing the electrode string end for end is at present the only practical method. Provided the signal from the sea has not changed, this $180^{\circ}$ reversal yields two voltages

$$
\begin{aligned}
& \left(\mathrm{E}_{2}-\mathrm{E}_{1}\right)-\Delta \mathrm{V}_{s}^{\prime}=\mathrm{V}_{1} \\
& \left(\mathrm{E}_{2}-\mathrm{E}_{1}\right)+\underline{\Delta V}_{\mathrm{s}}^{\prime}=\mathrm{V}_{2}
\end{aligned}
$$

$\mathrm{V}_{\mathrm{z}}$, the zero point, is therefore simply the average,

$$
\frac{V_{1}+V_{2}}{2}=V_{z}
$$

This can be most simply treated numerically if $V_{1}$ and $V_{2}$ are read from some arbitrary line on the strip chart far enough left to make both voltages positive. The average, $\mathrm{V}_{z}$, is located on the strip chart with respect to that same line.

(c) The courses that will yield data for calculating the true current at predetermined intervals involve turns of from $60^{\circ}$ to $120^{\circ}$. In order to keep track of the zero point the electrode positions must be transposed by a turn through $180^{\circ}$ at intervals of about an hour. If the electrodes are simply towed astern the ship itself must turn in to these courses and execute the sequence of turns over and over again. The $180^{\circ}$ turn can be eliminated if the ship is held on a steady course and the reversal effected by hauling in a line attached to the more distant electrode. This line or wire simplifies sailing but adds its own peculiar difficulties in that it may foul the electrode cable in bad weather, pick up clusters of sargassum, or tangle with other under way instruments. Means for improving the reversing line technique are presently being studied at sea on the Atlantis. The sailings possible with a reversing line attached to the electrodes are quite different from those that must be followed with only the simple tow, although any sailing plan possible without a reversing line is also possible with it. The sailing plans thus far used for current surveys in deep water have been designed to delay the ship as little as possible. On one-day trips and for bottom controlled experiments it has been the practice to make potential measurements along the four sides of a square or down and back along a dog-leg over the station. Since both squares and dog-legs return the ship to her starting point they are seldom used at sea except for repeated studies of a given patch of water.

Deep sea sailings without reversing gear may be run in at least two ways as shown in figure ${ }_{5} 5$ beside AI and A2. The AI course plan retards the ship Io or 15 per cent depending on her speed but provides the data for four current fixes per hour, one zero point determination per hour, and the component of flow normal to the principal course continuously. The A2 course plan retards the ship about 20 per cent if a course change is made every half hour but only 10 per cent if hourly. The $\mathrm{A}_{2}$ plan has one great 

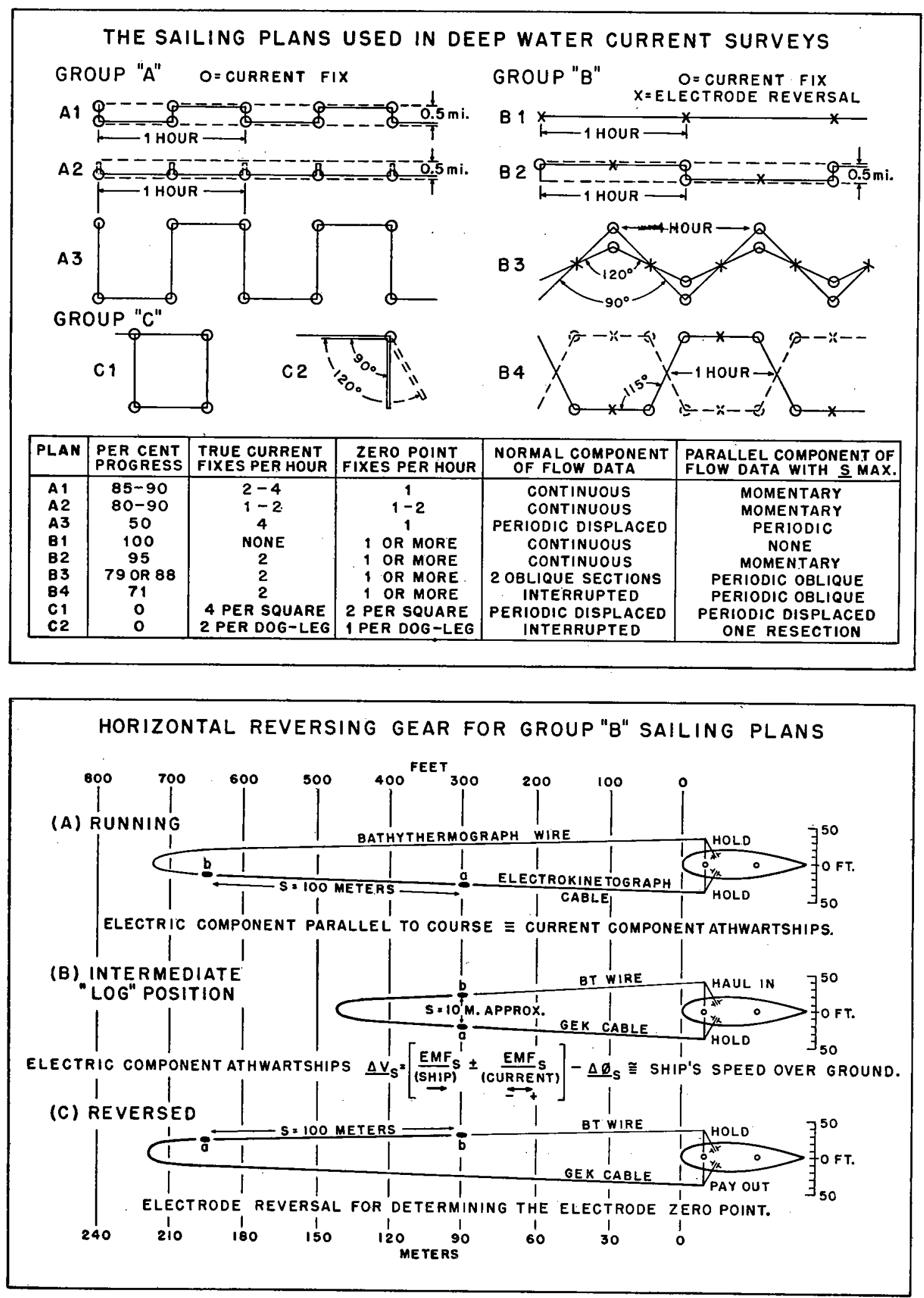

Fig. I 5 
advantage over the AI plan in that it reverses the electrodes through the same water and avoids the assumption that the water motion parallel to the principal course has not changed between successive headings $180^{\circ}$ to each other. In a slow ship in homogeneous water this assumption leads to no serious error, but in a fast ship or near a major ocean current it may do so. The A2 plan provides either I or 2 pairs of superimposed current fixes per hour, I or 2 zero point observations and continuous data on the normal component of flow. The A3 plan provides the same data as Ai but the current fixes are distributed in a way that lends itself to studies of an area by combining it with the ladder search plan. It is interesting to note that the sailing plans involving progress from port to port resemble classic Greek frets which are simply a running design between two parallel lines. The $A_{1}, A_{2}$ and $A_{3}$ course plans are variants of the dentil or dog-tooth fret. The Greek key and wave motif may also be useful at times in surveys with non-reversing cables.

The sailing plans in the $\mathrm{B}$ group of figure 15 lack the $180^{\circ}$ reversals characteristic of the A group. Since the $180^{\circ}$ reversal is accomplished by means of the reversing line it becomes possible to sail a straight course $(\mathrm{BI})$ with adequate knowledge of the zero point. The BI course plan retards the ship o per cent but only the normal component of flow can be observed. To fix on the true current at hourly intervals the $\mathrm{B}_{2}$ plan may be used. Since the zero point is determined as often as needed by means of the reversing line the interval between jogs from one side of the pattern to the other may be increased over that specified in AI to any convenient interval. If hourly intervals are used the ship is retarded about 5 per cent. On first thought the zig-zag sailing plan $B_{3}$ seems most logical and efficient. If the course change amounts to $60^{\circ}$ the retardation is 12 per cent. If the course change is $90^{\circ}$ the retardation is 21 per cent. Together with high retardation factors these courses do not provide a clear section of the normal component of flow, albeit the parallel legs can be summarized as two divergent sections that do not actually diverge. The double zig-zag or ogee plan may have some advantages in two-ship survey operations in providing frequent cross checks of results.

Courses in the $\mathrm{C}$ group of figure $\mathrm{I}_{5}$, the square $\mathrm{C}_{1}$ and dog-leg $\mathrm{C}_{2}$ are two possibilities that have been used for station work on one-day cruises. In early work with the electromagnetic method the square plan was used in conjunction with the Ai dentil plan to establish the validity of current fixes at jogs compared with the fixes obtained from the average of the voltages observed in running squares. There was generally about the same difference between successive corners of a square as between the average for the whole square and one jog.

The matter of sailing plans is considered still unsettled. Curved course plans are undesirable because the electrodes trailing astern make an unknown angle with the keel and the lubber line of the compass. In making use of the course plans discussed above it is often desirable to depart from routine to correct the set of the ship in swift currents. In sailing squarely through swift currents the ship is inevitably set downstream so that the track cuts obliquely through the streamlines. It is possible to lengthen the upstream legs of the course plan to counteract the drift, or to alter the on-course heading as explained under Class VI Experiments in section IV.

It must be emphasized that the complexity of sailings and reversal techniques is necessitated by the drifting zero point of the electrodes. If and when stable electrodes 
become available it will be possible to shorten the interelectrode distance to such an extent that two pairs of electrodes may be towed simulteneously, one parallel and one perpendicular to the course so that true currents will be observed continuously and only a straight course will be required. An attempt in this direction is being tested at sea by halting the line reversal at the point where the electrodes lie opposite each other on the line normal to the course. The signal strength is bound to be small because the interelectrode length is small, and the signal will include the ship's way, but the attempt seems worthwhile. A separate athwartships array was used experimentally on the Atlantis during part of Cruise I49, but it was necessary to back the ship down to determine the zero point. The present technique avoids this and is outlined in figure 15 .

\section{The Reduction of Observations at Sea}

To utilize the Electrokinetograph effectively at sea it is necessary to compute the results of voltage measurements as they are recorded. Knowing the current prevailing in the region through which the ship is sailing it is possible to alter sailing plans in the manner most advantageous to both the observations and the efficient navigation of the ship.

In reading the voltage signals on the strip chart some variability of results will be inevitable from person to person. The principal sources of this variability arise in (a) making estimates of the average voltage due to the mean water current through the confusion of turbulence and wave signals, and (b) making estimates of the beginning and ends of each turn signal. It has been found that better results are obtained in determining the average voltage if this is done entirely by eye without the use of pencil marks or a ruler. Any personal equation of error in this eye average is likely to balance out, since the estimates by given individuals probably will be systematically to the right or to the left. The estimation of the beginning and end of a turn signal, produced by the lateral motion of the towed cable cutting inside the turning circle of the ship, can be aided by measuring the interval of time between execution of a turn and reception of the beginning of the turn signal. The turn signal lasts as long as the ship's turning time and is received approximately $\mathrm{L} / \mathrm{C}_{\mathrm{s}}$ minutes after the ship entered the turn, where $\mathrm{L}$ is the length of cable towed astern and $\mathrm{C}_{\mathrm{s}}$ is the ship's speed. Anticipating and marking the beginning and ending of the turn signals as they occur will improve the consistency of interpretation of the data both at sea and in later study of the records. It is well to be extravagant in delineating the turn signals for if the voltage shift on two courses is large, both the electrodes and the condenser banks in the wave signal suppressor must have time to come to equilibrium. Characteristic turn signals can be seen in figure I6 between the time markings I927-1929, I931-r933, I957-1959 and 2002-2004 made while sailing the AI course plan. Note that the turn signals follow the indicated course changes by about one minute of time. The ship's speed was approximately 300 meters per minute and the length of cable towed astern about 300 meters.

The fix signals [to be found in figure 16 between time markings I929-I93I and I959-2002] are usually parallel to the time axis. The fix signal between 1959-2002 at first glance appears oblique or curved. Probably the interval 1958-2000 represents an overshoot or other steering error caused by the change of helmsman with the watch. Best results are obtained if the first half of a fix signal is viewed with suspicion and 


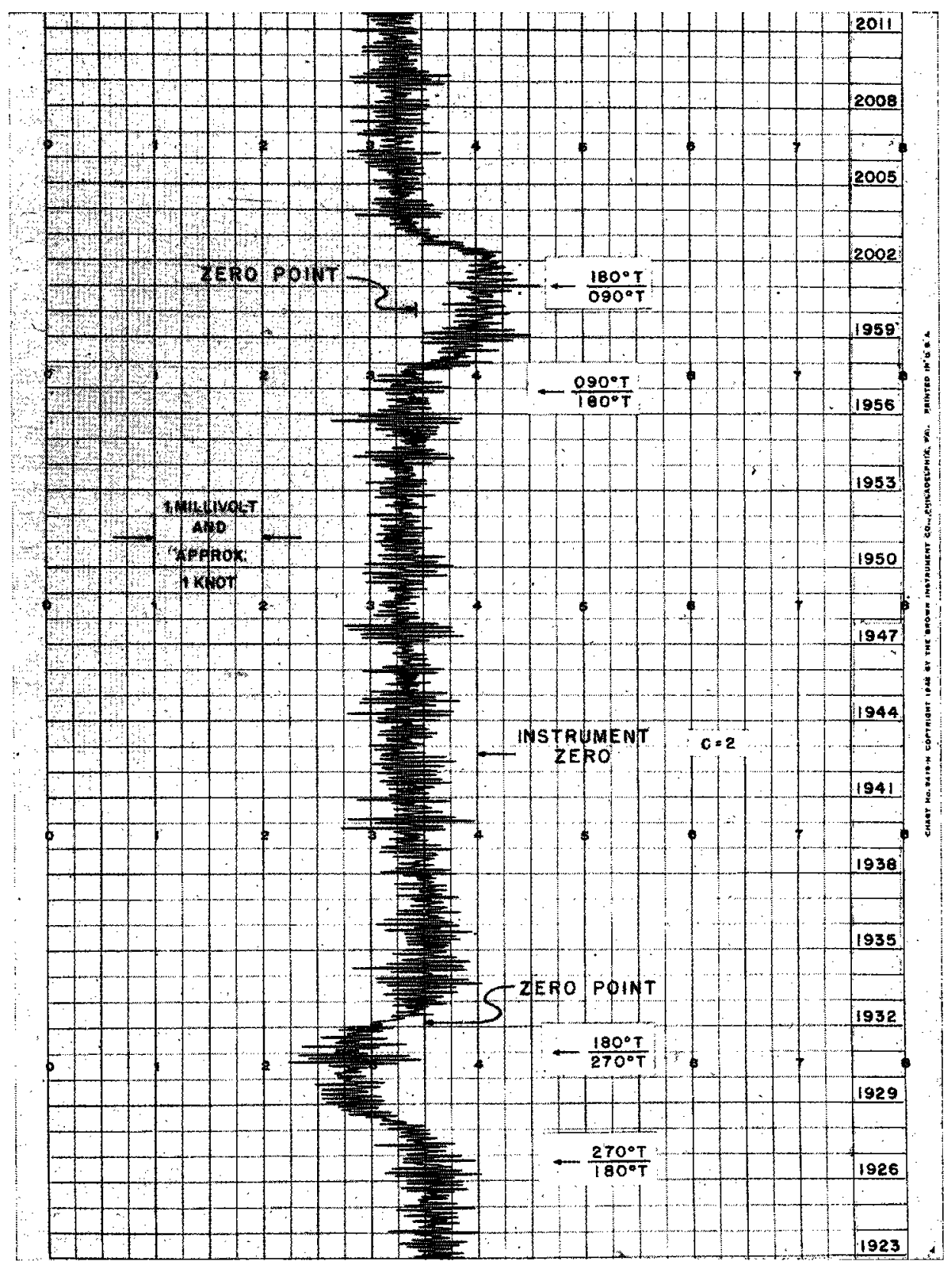

FIg.I6. An illustrative sample of the record trace obtained on sailing plan AI. The long segments of the trace were recorded on the 26-minute on-course leg and represent the component of water motion normal to the course. The shorter segments were recorded on the 4-minute legs at $90^{\circ}$ to the principal course made every half hour in the Ai plan. The course changes are entered as they were made at the helm. The signal lags the execution of the course change directly in proportion to the length of cable towed astern, and inversely as the speed of the ship.

The numbered vertical rules are I millivolt apart and roughly correspond to $\mathrm{I}$ knot of athwartships drift. The horizontal rules are 1 -minute apart in time and $1 / 3$-inch apart on the original. Time grows later upward as indicated by the entries at the right-hand margin. Instrument zero lies on rule number 4 and the "zero point"-or origin of measurement is indicated at each determination. This 45-minute segment of trace provides two determinations of true current, the intervening normal component of flow, and data on wave periods. The current velocities are calculated for this trace in table 4 . 


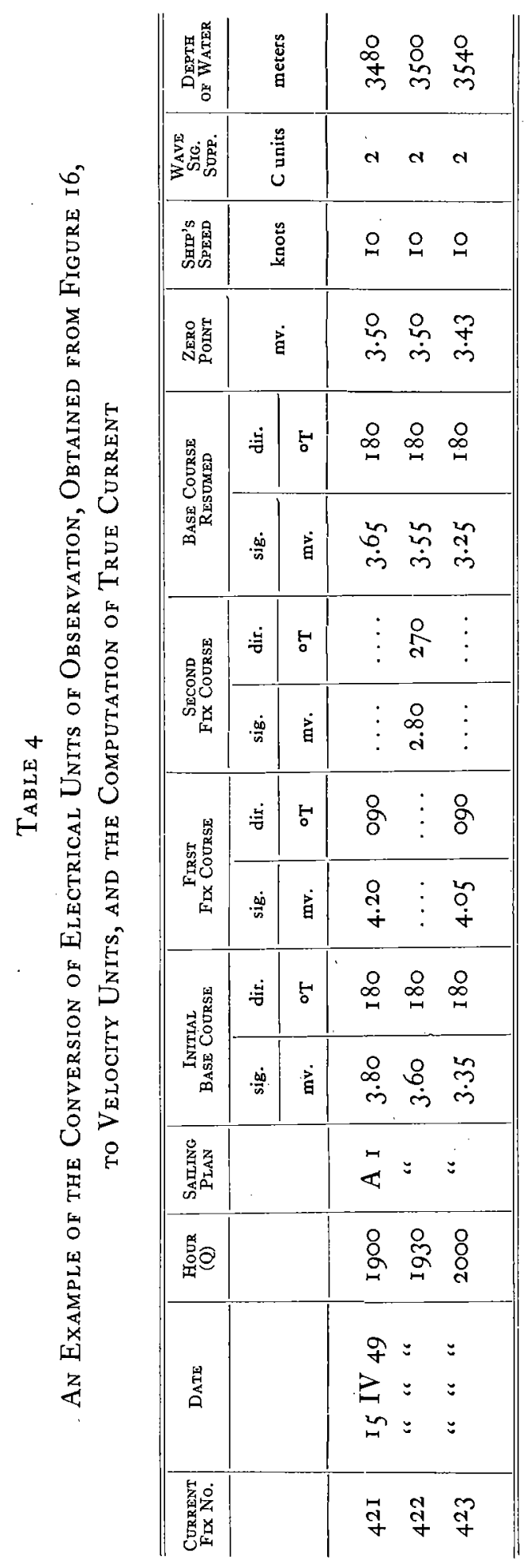

\begin{tabular}{|c|c|c|c|}
\hline \multirow{2}{*}{ 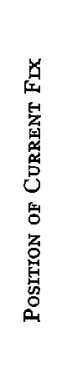 } & \multicolumn{2}{|c|}{ 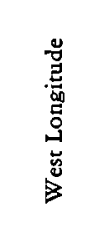 } & 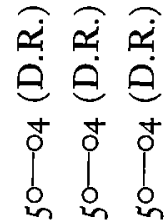 \\
\hline & \multicolumn{2}{|c|}{ 起营 } & 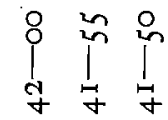 \\
\hline \multirow{2}{*}{ 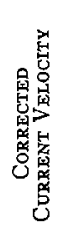 } & 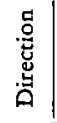 & 苂 & $\stackrel{\infty}{\infty} \underset{\sim}{\infty} \stackrel{\infty}{\infty}$ \\
\hline & $\begin{array}{l}\overrightarrow{\mathrm{U}} \\
\stackrel{\mathrm{D}}{\mathrm{s}}\end{array}$ & : & 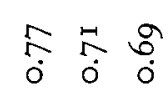 \\
\hline 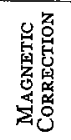 & \multicolumn{2}{|c|}{ 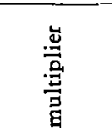 } & 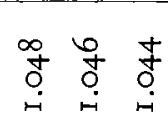 \\
\hline \multirow{2}{*}{ 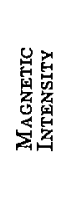 } & 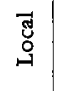 & \multirow{2}{*}{ 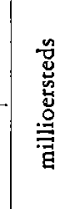 } & 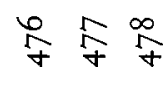 \\
\hline & 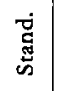 & & $\stackrel{8}{8} \stackrel{8}{\circ}$ \\
\hline \multirow{2}{*}{ 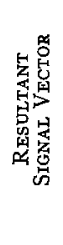 } & 逭 & $F$ & 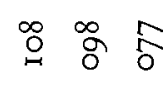 \\
\hline & 袺 & $\dot{\theta}$ & 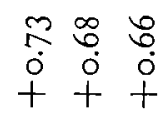 \\
\hline \multirow{2}{*}{ 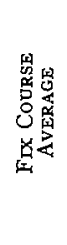 } & $\dot{\vec{g}}$ & $\mathrm{H}$ & \& \\
\hline & 跑 & $\dot{\vec{\theta}}$ & $\begin{array}{lll}\circ & \infty & + \\
\stackrel{0}{0} & 0 & 0 \\
+ & 1 & +\end{array}$ \\
\hline \multirow{2}{*}{ 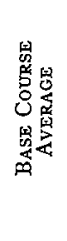 } & : & $H$ & $\begin{array}{lll}0 & 0 & 0 \\
\infty & \infty & \infty \\
\sim & \infty & \infty \\
\sim\end{array}$ \\
\hline & : & है & $\begin{array}{lll}\text { ส } & 0 & 0 \\
0 & 0 & 1 \\
0 & 0 & 0 \\
+ & + & 1\end{array}$ \\
\hline
\end{tabular}


greatest weight is given the latter portion of the trace when the ship's heading, the electrochemical system of the electrodes, and the condensers in the wave signal suppressor system have all had time to come to equilibrium.

The wave signal suppression used during this recording is marked $\mathrm{C}=2$. This value was somewhat too low for the sea state existing at the time. A value of 6 or 8 would have narrowed the fringe of the wave signal to the extent shown in figure I I and made estimates of the voltages much easier.

The voltages indicated in figure 16 are in millivolts. The instrument zero lies on the line labeled 4 and the range is plus and minus 4 millivolts to the right and left respectively of this line. Since the electrode zero point does not necessarily coincide with the instrumental zero line, arbitrary numbering from the left-hand margin is convenient. The indicated voltages and other data for figure 16 are tabulated above, in table 4 , and the whole computation of the true current at the I900, I930 and 2000 fixes has been done to illustrate the procedure that has been found useful. The voltages recorded for the base course are limited to the 5 minutes preceding the initial turn signal and the 5 minutes following the turn signal at the completion of the fix.

It is a natural consequence of any continuous recording measurement process that the record charts contain candid details that will bear endless amounts of study. It is clear even now that efficient exercise of the full powers of the electromagnetic method depends on the development of analytical techniques that are rapid and impartial, yet intimate enough to permit the analyst to recognize new phenomena as the records pass before him. The development of analytical techniques can be simplified by a successful study of the electrode problem. Were it not for the instability of the potential of present electrodes it would be possible to design apparatus that would record the true water velocity continuously. This development is potentially as important to deep water navigation as to oceanography. Electromagnetic aids to everyday deep water navigation could also yield detailed and automatic measurements of currents such as are now obtained only by research vessels. At present, developments of this kind would involve approximation of the zero point. While developments based on this approximation might be useful in navigation, they would tend to divert attention from the essential difficulty. One successful development in electrode design would make use of the electromagnetic method both convenient and inherently precise, and further simplify the already quite simple problems of navigational and oceanographic instrumentation. 


\section{APPLICATION OF THE ELECTROMAGNETIC METHOD TO OBSERVATIONS IN SHOAL WATER}

The reference frame provided by the earth's magnetic field can be used in shoal water through two adaptations of the electromagnetic method. The first involves modified use of the Geomagnetic Electrokinetograph. Certain changes of observing procedure are required. In the second adaptation, measurements are made of the electric potential differences due to water flow between electrodes at rest.

\section{i. Observations While Under Way}

While it was pointed out that the Electrokinetograph is most precise in deep water, it may be used wherever there is sufficient sea room to maneuver a ship or launch. In shoal water the signal strength will be found to be too small for the magnitude of the water velocity but on the whole the direction will be substantially correct. The defect in signal strength can be estimated either through calibration against another method of measurement or by direct measurement of the cause of the signal strength deficiency. The signal is deficient by $\Delta \phi_{s}$, the amount of the electric potential field intensity between the electrodes at rest. The electric potential field intensity is determined by the degree of imperfection of the short circuit provided by the local resistivity of the sea bed and the thickness of the quieter layers of water over the bottom. In shoal waters currents usually extend to the bottom where the electrical resistivity may be highly variable even in a small region. The defect of signal strength and the electric field intensity will vary correspondingly. Thus frequent direct measurements must be made of the local electric field intensity and defect of signal strength.

It will be recalled that the resultant observed signal under way is $\Delta \mathrm{V}_{\mathrm{s}}$. This value added to the intensity of the electric field, $\Delta \phi_{s}$, yields the total motional electromotive force, Emf, characteristic of the water motion, (see equation III-g). Theoretically the intensity of the electric field can be measured directly if the cable and detecting electrodes are at rest on the bottom. If the observing ship is run dead slow the electrodes will sink until one can feel them drag on the bottom. As soon as they drag and the ship is stopped, a reading will be obtained for $\Delta \phi_{s}$. The same procedure followed on another heading, preferably at right angles, will provide a value of $\Delta \phi_{s} y$. These values may be composed to give the magnitude and direction of the electric field intensity on the bottom. To obtain the corresponding under way signal the ship is then sailed around a square centered on this point. In order to simplify reduction of the data from the squares it has been found desirable to average the voltages observed on parallel sides. These averages can then be composed to give a single electric vector and a single velocity vector which is probably characteristic of the water motion within the square, at that time. Table 5 contains data illustrating this type of observation at one shoal station in Nantucket Sound. 


\section{Table 5-A Bottom Corrected Measurement of Surface Current in the Western Part of Nantucket Sound}

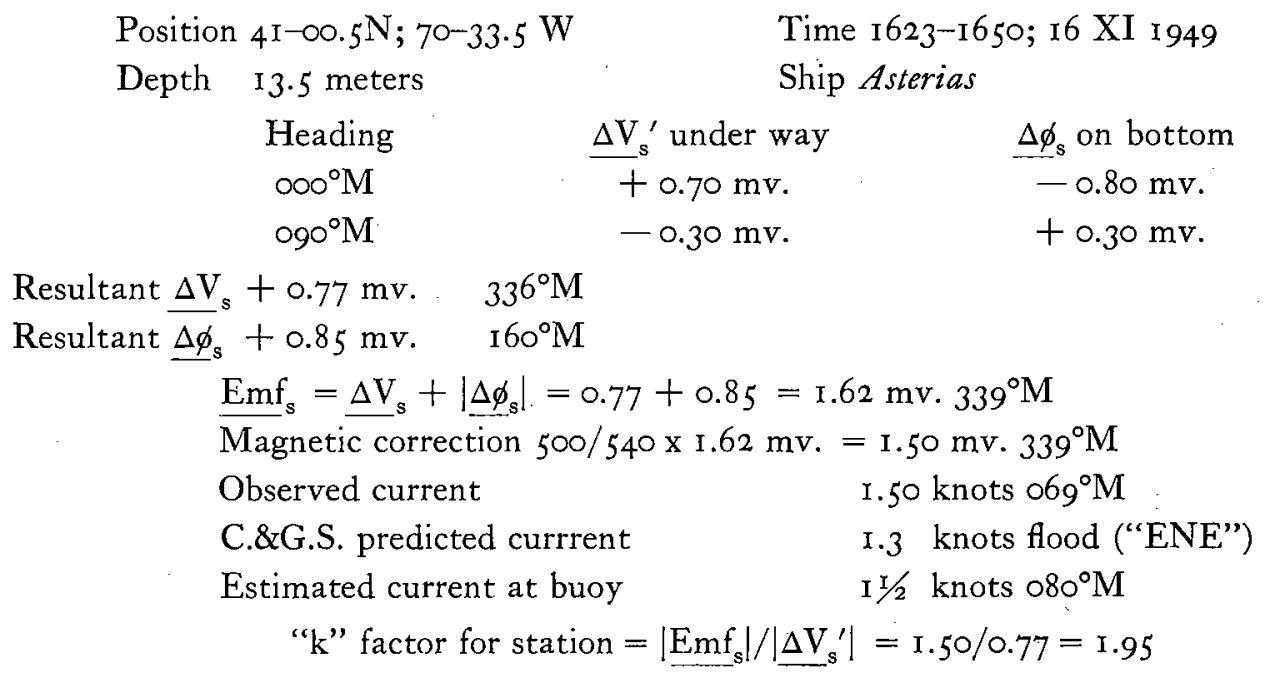

Due to errors in averaging and the variety of water motions from surface to bottom in tidal reaches the electric field vectors measured at rest and under way may not lie in the same vertical plane. If the angular error is large the bottom measurement at rest is probably not representative of the average conditions over the bottom, in which case the direction of the average electric vector at the surface is a better choice, or the bottom observations should be repeated. In areas where the bottom resistivity is very high and the water current extends to the bottom the value of the electric field intensity at the bottom may be greater than that of the motional electric vector measured under way.

The errors involved in this application of the Electrokinetograph are theoretically small $\left[\left(\Delta \mathrm{V}_{s}^{\prime}+\left|\Delta \phi_{s}\right|\right) / \mathrm{Emf}_{s}\right]$, but may be practically considerable because of the possible variation of $\Delta \phi_{s}$ from bottom to surface and from place to place horizontally. In shoal waters, less than io meters deep, earth currents may also complicate the signals and confuse the observations. In greater depths of water the variability of results is significantly diminished. On the continental shelves in depths of roughly roo meters of water it is difficult to feel the electrodes run aground and to handle the ship with certainty. Under way readings taken at their face value over broad flat stretches of bottom are probably consistent among themselves although their magnitudes may be systematically from $20 \%$ to $50 \%$ too small. It therefore seems possible to risk fewer bottom potential measurements in these areas without producing great internal inconsistency in the results. This kind of measurement has been studied only in passing on the way to explore the deep water potentialities of the Electrokinetograph and relatively little is known of its practical application. The feasibility of the method for surveys of the currents on the continental shelves is clearly shown, however, in figure 4 , which is a portion of a cruise of U.S.C.G. Cutter Evergreen over the southern part of Georges Bank. Here rotary tides are characteristic and these can be followed from just beyond Nantucket Lightship as far east as Corsair Canyon. 


\section{Observations at a Fixed Station}

The second adaptation of the electromagnetic method is in a sense the alternative to the Electrokinetograph. It is the principle Faraday had in mind originally. It was successfully applied by Young, Gerrard and Jevons (op.cit., I920) and the case very thoroughly studied by Longuet-Higgins (op.cit., I947, 1949), Barber and Longuet-Higgins (op.cit., I948) and Barber (I948). In this case the measuring apparatus is at rest and therefore free of induced potentials. The signal recorded is proportional to the electric potential field generated in the water by its motion through the earth's magnetic field. In order for the intensity of this signal to be given by the product $\left(\mathrm{H}_{2} \mathrm{sv}\right) \times \mathrm{IO}^{-8}$ volts, the water motion must be free of shear and the sea bed resistance must be infinite. Since neither of these requirements is ever satisfied in nature the signal received is always too small. For a given station and installation, however, the deficit is roughly constant.

If measurements are to be made in a channel or open arm of an estuary where turbulence is slight and upwelling and sinking absent it may be assumed that $v_{z}=0$. The velocity components $\left(v_{x} i+v_{y} j\right)$ define the horizontal flow, and $E$ will be perpendicular to it. If measurements are made in only the xy plane and at right angles to the flow, again $\mathrm{H}_{\mathrm{z}}$ alone will be of physical consequence for $\mathbf{v}$ will be fully determined by $\left(\Delta \mathrm{V}_{s \mathrm{x}} \mathbf{i}+\right.$ $\left.\Delta \mathrm{V}_{\text {sy }} \mathbf{j}\right) / \mathrm{H}_{\mathrm{z}}$ as in equation (III-5). If electrodes a distance s apart are fixed at opposite sides of a channel perpendicular to the indicated flow and joined by a cable at rest, the potentiometer in series will indicate $\Delta \mathrm{V}_{\mathrm{s}}^{\prime}=\Delta \phi_{\mathrm{s}}$. Since the water depth and general environmental conditions remain nearly constant the signal is nearly proportional to, and changes sign with, the direction of the average water velocity.

The zero point of short range fixed electrode systems is difficult to determine. Physical reversal is awkard unless the electrodes can be disconnected and transposed so rapidly that the motional signal will not have time to change significantly. The zero point has been more often determined from the average signal at slack water. This signal is not entirely reproducible because of interference from earth current potentials and the variation of the time of slack water in other parts of the channel, or in other channels near enough to contribute to the signal. If the flow up and down the channel is known to be symmetrical or characteristically assymmetrical, some estimate of "electrical slack" can be made from the appearance of the recorded trace. On very long ranges (greater than $10 \mathrm{~km}$ ) the zero point error is likely to be small compared with the motional signal.

The tidal signal of a turbulent stream flowing over a very rough bottom doubtless contains signals due to the irregular vertical velocities interacting with the horizontal components of the earth's magnetic field. Earth currents, which have been shown by Barber (op.cit., I948) and Barber and Longuet-Higgins (op.cit., I 948) to collect in channels, also contribute a fluctuating term to the record character of the observed potential differences. Figure 17 is a sample from an 18 -month record of an experiment in the local environment near Woods Hole. 


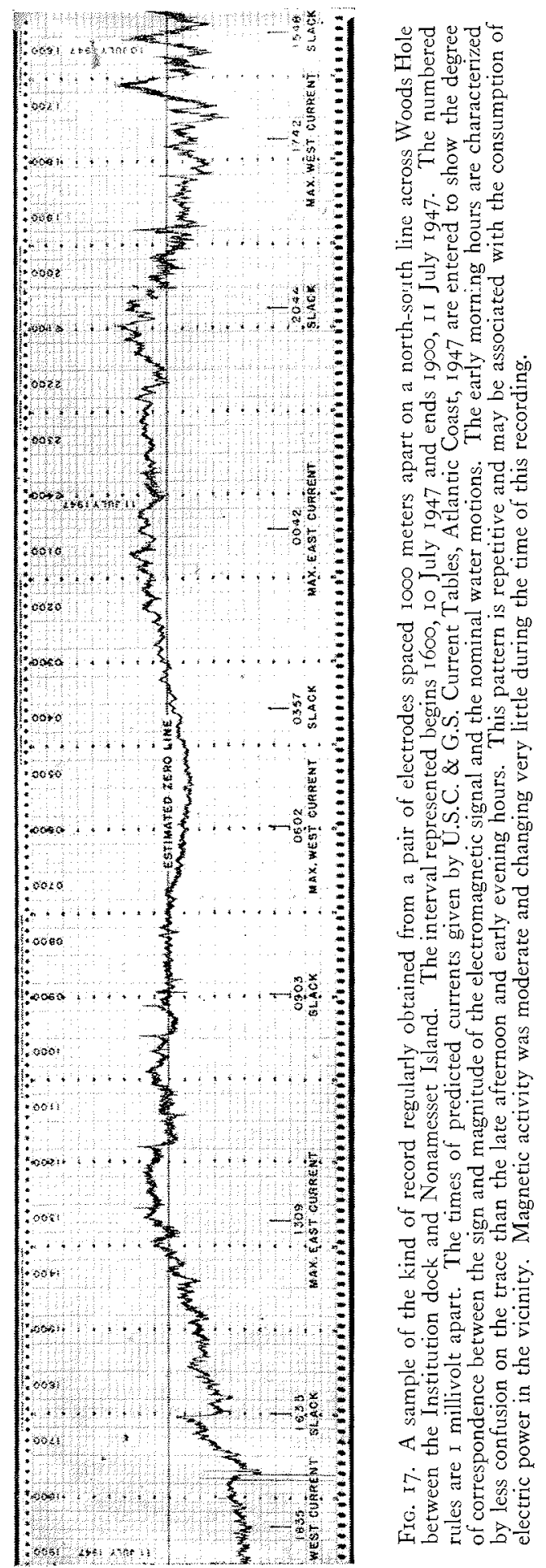

60 


\section{REFERENCES}

BARBER, N. F., I948: The magnetic field produced by earth currents flowing in an estuary or sea channel. Mon. Not. Roy. Astr. Soc., Geophys. Suppl., 5(7):258-269.

Barber, N. F. and M. S. Longuet-Higgins, I948: Water movements and earth currents: electrical and magnetic effects. Nature I6I:192-I93:

Chapman, S. and J. Bartels, i940: Geomagnetism. London, Oxford University Press, 2 vols., IO49 pp.

Einhorn, H. D., 1939: Electro-magnetic induction in water. Trans. Roy. Soc., S. Africa, 28:143-160.

FABRE, P., I932: Utilisation des forces electromotrices d'induction pour l'enregistrement des variations de vitesse des liquides conducteurs: un nouvel hemodromographe sans palette dans le sang. Comp. Rend. Acad. Sci., Paris 194:1097-1098.

FARADAY, M., I832: Art. VI., The Bakerian Lecture.- Experimental Researches in Electricity.- Second Series. Sec. 5. Terrestrial Magneto-electric Induction. Phil. Trans. Roy. Soc. London, I832: Part I, I63-I77 [vid. 176, par. I90].

Fleming, J. A., (Ed.) 1939: Physics of the Earth - VIII. Terrestrial magnetism and electricity. New York, McGraw Hill Book Co., 794 pp.

Guelcke, R. W. and C. A. Schoute-VAnneck, I947: The measurement of sea water velocities by electromagnetic induction. Four. Inst. Elec. Eng., 94, Part II (37): 7I-74.

Kolin, A., I936: An electromagnetic flowmeter. Principle of the method and its application to bloodflow measurements. Proc. Soc. Exp. Biol. and Med. 35:53-56.

Kolin, A., I944: Electromagnetic velometry. I. A method for the determination of fluid velocity distribution in space and time. Four. Applied Phys. I5(2):I50-164.

KolIn, A., 1945: An alternating field induction flow meter of high sensitivity. Rev. Sci. Insts. I6(5):109-I I6.

Longuet-Higgins, M. S., I947: The electric field induced in a channel of moving water. Admiralty Research Laboratory, Teddington, Report ARL/R.2/IO2.22/W (mimeographed report).

Longuet-Higgins, M. S., I949: The electrical and magnetic effects of tidal streams. Mon. Not. Roy. Astr. Soc., Geophys. Suppl., 5(8):295-307.

Longuet-Higgins, M. S. and N. F. BARBer, I946: The measurement of water velocity by electromagnetic induction. An electrode flow-meter. Admiralty Research Laboratory, Teddington, Report ARL/R.I/I02.22/W (mimeographed report).

Soule, F. M., H. H. Carter and L. A. Cheney, (in press): International ice observation and ice patrol service in the North Atlantic Ocean - season 1948. U.S. Coast Guard Bull. 34.

Soule, F. M., (in preparation): International ice observation and ice patrol service in the North Atlantic Ocean - season 1949. U. S. Coast Guard Bull 35. 
Southwell, R. V., 1946: Relaxation methods in theoretical physics. London, Oxford University Press. $248 \mathrm{pp}$.

Stommel, H., I948: The theory of the electric field induced in deep ocean currents. 7. Mar. Res. 7(3):386-392.

Thürlemann, B., I94I: Methode zur elektrischen Geschwindigkeitsmessung von Flüssigkeiten. Helvetica Physica Acta I4(5-6):383-4I9.

Vestine, E. H., Lucile Laporte, Isabelle Lange, W. E. Scott, i947: The geomagnetic field, its description and analysis. Carnegie Inst., Washington, Dept. Terrestrial Magnetism, Pub. 580, 390 pp.

Vistine, E. H., Lucile Laporte, Caroline Cooper, Isabelle Lange, W. C. Hendrix, 1948: Description of the earth's main magnetic field and its secular change, I905I945. Carnegie Inst., Washington, Dept. Terrestrial Magnetism, Pub. 578, $53^{2}$ pp.

Wetterer, E., 1937: Eine neue methode zur Registrierung der Blutstromungsgeschwindigkeit am uneröffneten Gefäss. Zeit. für Biologie 98:26-36.

- - 1938: Eine neue methode zur Registrierung der Blutströmungsgeschwindigkeit am uneröffneten Gefäss. (2. Mitteilung.) Zeit. für Biologie 99:1 58-162.

Williams, E. J., 1930: The induction of electromotive forces in a moving liquid by a magnetic field, and its application to an investigation of the flow of liquids. Proc. Phys. Soc., London, $42: 466-487$.

Young, F. B., H. Gerrard and W. Jevons, I920: On electrical disturbances due to tides and waves. Phil. Mag. Ser. 6, 40:149-I59. 
Vol. VI, No. I. H. R. Seiwell: Application of the Distribution of Oxygen to the Physical Oceanography of the Caribbean Sea Region, 1938.

No. 2. R. B. Montgomery: Circulation in Upper Layers of Southern North Atlantic Deduced with Use of Isentropic Analysis, $193^{8}$.

No. 3. H. G. Houghton and W. H. Radford: On the Local Dissipation of Natural Fog, I938.

No. 4. H. G. Houghton and W. H. Radford: On the Measurement of Drop Size and Liquid Water Content in Fogs and Clouds, I938.

Vol. VII, No. I. C.-G. Rossby, Jerome Namias, and Ritchie G. Simmers: Fluid Mechanics Applied to the Study of Atmospheric Circulations, Part I. A Study of Flow Patterns with the aid of Isentropic Analysis, I938.

No. 2. S. Petterssen and J. M. Austin: Fronts and Frontogenesis in Relation to Vorticity, I 942.

No. 3. H. R. Seiwell: The Effect of Short Period Variations of Temperature and Salinity on Calculations in Dynamic Oceanography, I939.

No. 4. R. B. Montgomery: Observations of Vertical Humidity Distribution above the Ocean Surface and their Relation to Evaporation, 1940. O Out of Print

Vol. VIII, No. I. C. O'D. Iselin: Preliminary Report on Long-Period Variations in the Transport of the Gulf Stream System, I940.

$0.75 \dagger$

No. 2. F. A. Brooks: Observations of Atmospheric Radiation, I94I.

$0.50^{*}$

No. 3. R. A. Allen, R. Fletcher, J. Holmboe, J. Namias and H. C. Willett: Report on an Experiment in Five-Day Weather Forecasting, 1940. Out of Print

No. 4. M.A. Garstens: Some Effects of Shearing Motion on the Propagation of Waves in the Prevailing Westerlies, I94I.

$0.75^{*}$

Vol. IX, No. I. H. C. Willett: Report of the Five-Day Forecasting Procedure, Verification and Research as Conducted between July, I940 and August, I94I, I94I.

No. 2. A. C. Redfield: The Processes Determining the Concentration of Oxygen, Phosphate and other Organic Derivatives within the Depths of the Atlantic Ocean, 1942.

No. 3. J. M. Austin: Cloudiness and Precipitation in Relation to Frontal Lifting and Horizontal Convergence, I 943.

No. 4. T. F. Malone: A Study of Interdiurnal Pressure and Temperature Variations in the Free Atmosphere over North America, 1946.

I.00*

$0.50 \dagger$

$0.75^{*}$

$0.75^{*}$

Vol. X, No. I. Richard A. Craig: Measurements of Temperature and Humidity in the Lowest 1000 feet of the Atmosphere over Massachusetts Bay, 1946.

No. 2. Frederick C. Fuglister: Average Monthly Sea Surface Temperatures of the Western North Atlantic Oçean, 1947.

$0.50 \dagger$

No. 3. Gardner Emmons: Vertical Distributions of Temperature and Humidity over the Ocean between Nantucket and New Jersey, I947.

No. 4. H. R. Seiwell: Results of Research on Surface Waves of the Western North Atlantic, I948.

I.00†

Vol. XI, No. I. A. F. Bunker, B. Haurwitz, J. S. Malkus, and H. Stommel: Vertical Distribution of Temperature and Humidity over the Caribbean Sea, I949.

No. 2. Henry C. Stetson: The Sediments and Stratigraphy of the East Coast Continental Margin; Georges Bank to Norfolk Canyon, I949.

No. 3. William S. von Arx: An Electromagnetic Method for Measuring the Velocities of Ocean Currents from a Ship Under Way.

* Requests for this number should be addressed to Meteorological Department, Massachusetts Institute of Technology, Cambridge, Massachusetts.

$\uparrow$ Requests for this number should be addressed to Woods Hole Oceanographic Institution, Woods Hole, Massachusetts. 